\title{
Flexible Polyurethane Foams from Epoxidized Vegetable Oils and a Bio-Based Diisocyanate
}

\author{
Angelica Cifarelli (D), Laura Boggioni (D), Adriano Vignali (D), Incoronata Tritto (D), Fabio Bertini (D) \\ and Simona Losio *(D)
}

Citation: Cifarelli, A.; Boggioni, L.; Vignali, A.; Tritto, I.; Bertini, F.; Losio, S. Flexible Polyurethane Foams from Epoxidized Vegetable Oils and a Bio-Based Diisocyanate. Polymers 2021, 13, 612. https://doi.org/ $10.3390 /$ polym 13040612

Academic Editor: Marcelo Antunes Received: 29 January 2021

Accepted: 15 February 2021

Published: 18 February 2021

Publisher's Note: MDPI stays neutral with regard to jurisdictional claims in published maps and institutional affiliations.

Copyright: (c) 2021 by the authors. Licensee MDPI, Basel, Switzerland. This article is an open access article distributed under the terms and conditions of the Creative Commons Attribution (CC BY) license (https:// creativecommons.org/licenses/by/ $4.0 /)$
Institute for Chemical Sciences and Technologies "G. Natta" National Research Council, Via A. Corti 12, 20133 Milan, Italy; angelica.cifarelli@scitec.cnr.it (A.C.); laura.boggioni@scitec.cnr.it (L.B.); adriano.vignali@scitec.cnr.it (A.V.); incoronata.tritto@scitec.cnr.it (I.T.); fabio.bertini@scitec.cnr.it (F.B.)

* Correspondence: simona.losio@scitec.cnr.it; Tel.: +39-02-23699-369

\begin{abstract}
Bio-polyols from epoxidized soybean and linseed oils and caprylic acid or 3-phenyl butyric acid were prepared using an environmentally friendly, solvent-free method evaluating the presence of triethylamine as catalyst. Side reactions, leading to a cross-linking structure with high density, were reduced, introducing the catalyst and properly tuning the reaction conditions. A medium functionality value of around 3 along with a hydroxyl number up to around $90 \mathrm{mg} \mathrm{KOH} / \mathrm{g}$, narrow polydispersity index, and relatively low molecular mass up to $2400 \mathrm{~g} / \mathrm{mol}$ were the experimental targets. From selected bio-polyols and an aliphatic partially bio-based isocyanate, a series of water blown polyurethane (PU) foams was produced, estimating the effect of the chemical nature of substituents in the polyol backbone on the PU properties. The apparent density of the foams was in the range of $79-113 \mathrm{~kg} / \mathrm{m}^{3}$, with higher values for foams from the aromatic acid. Flexible polyurethane foams with open cell structure from bio-based polyols were obtained, with higher cavity size and lower pore sizes for foams from caprylic acid. The bio-based flexible PU foams showed comparable Young's moduli (14-18 kPa) and compression deflection values (4.6-5.5 kPa) and exhibited an almost complete recovery of their initial size.
\end{abstract}

Keywords: bio-polyols; bio-based isocyanate; flexible polyurethane foams; prepolymer synthesis; thermal and mechanical properties

\section{Introduction}

Polyurethanes (PUs) are a major polymer family [1], with a global market estimated at approximately $€ 53$ billion (sixth among all polymers). Due to the multiplicity of their structures and versatile properties, PUs can be used in various applications. They are mainly found as foams (rigid or flexible based on closed and open cells, respectively), but also as denser materials (elastomers, thermoplastics, or thermosets). PUs can also be used as blends with other polymers, as coatings, or as composites with fillers [2-6].

Nowadays, in agreement with sustainable development principles, a great number of studies and developments have been realized in the field of bio-based PUs, conventionally synthesized by reaction of polyols with isocyanates [7-9]. Vegetable oils have been extensively studied for their use in producing bio-based polyols [10,11]. They are readily available and offer advantages such as easy processing, chemical functionality, and relatively low cost. Except for castor and lesquerella oils, vegetable oils do not bear hydroxyl groups, thus they must be introduced at the unsaturated sites by chemical reactions. Among them, epoxidation reactions followed by ring-opening of the oxirane group have been widely investigated for the preparation of bio-based polyols [12-15]. These oxirane ring-opening reactions are generally conducted in the presence of ring-opening agents, such as alcohols or inorganic acids [13-17], at high temperatures and for long times because of the sterically hindered location of the oxirane groups inside the fatty acid chain. Moreover, these conditions promote side reactions leading to the formation of cross-linked structures 
in polyols that impact on the properties of the final products $[18,19]$. To overcome these issues and to favor the opening of internal epoxy groups in triglycerides, one approach is the use of catalysts, such as bases (e.g., amines), phosphorus compounds (e.g., triphenyl phosphine), metals (e.g., chromium compounds), and cationic catalysts (e.g., Lewis acids) [20]. Among them, amines have been widely investigated as nucleophilic reagents used to open the oxirane ring and show good catalytic effect in vegetable-oil-based epoxy systems [17]. In particular, Pan et al. reported the use of 1,8-diazabicyclo[5.4.0]undec-7-ene (DBU) as a catalyst in polyol preparation from epoxidized sucrose esters of soybean oil ring-opened by several organic acids [17]. Furthermore, Kessler et al. investigated the ring-opening between epoxidized soybean oil and linseed oil and castor-oil-based fatty acids in the presence of DBU and pyridine as catalysts [18].

However, although polyols prepared from vegetable oils offer a variety of new and interesting structures, their use is still limited since polyols from epoxidation/ring-opening reactions mostly contain secondary hydroxyl groups which are much less reactive towards isocyanates than those containing primary hydroxyl groups. Besides, the number of hydroxyl groups is considered a critical point affecting thermal and mechanical properties [21]. Furthermore, vegetable oils with high level of unsaturation lead to polyols with high $\mathrm{OH}$ functionality. This will result in an increase in cross-linking densities of the resulting PUs, which could limit or preclude their use in flexible foams that represent two-thirds of all polyurethane applications [22-24]. Furthermore, bio-based polyurethanes, in comparison to the petroleum-derived counterparts $[25,26]$, in PU applications have some limitations. This arises from their heterogeneous composition that may vary from geographic area but also from the limited compatibility with conventional polyols and other ingredients in PU formulations.

From the literature, it is evident that investigations have been particularly focused on bio-based polyols. In contrast, there has been comparatively little work on the use of bio-based diisocyanate. However, commercial versions of bio-based diisocyanate are now available. For example, Vencorex Chemicals (Saint-Priest, France) has commercialized an aliphatic diisocyanate named Tolonate ${ }^{\mathrm{TM}}$ coming from palm oil. This isocyanate possesses low viscosity, 25\% renewable material, and a green carbon content of around 32\% [27]. This isocyanate is generally employed as precursor to synthesize epoxy resin for coating applications. Nevertheless, to the best of our knowledge there are no examples related to the preparation of flexible polyurethane foams with Tolonate ${ }^{\mathrm{TM}}$.

Thus, we decided to investigate the use of bio-based diisocyanate Tolonate ${ }^{\mathrm{TM}}$ in combination with polyols from vegetable oils for the preparation of polyurethane foams. Moreover, an aliphatic diisocyanate could ensure flexibility to foams from vegetable-oilderived polyols, characterized by relatively low $\mathrm{OH}$ equivalent weight [22,23].

In this study, we report the synthesis of an innovative family of flexible bio-based polyurethane foams from bio-polyols and Tolonate ${ }^{\mathrm{TM}}$, with good appearance and mechanical properties, estimating the effect of the chemical nature of the substituents in the polyol backbone on the PU properties. Polyols were synthesized from commercial epoxidized soybean and linseed oil without the use of organic solvents by ring-opening reaction of the oxirane with organic acids under mild reaction conditions, thus obtaining polyols with different functionalities. A Lewis base catalyst, e.g., triethylamine (TEA), was evaluated to facilitate the ring-opening of internal epoxy groups of the epoxidized oil and minimize the formation of cross-linked structures to produce less viscous and more processable polyols with narrow polydispersity indices $[19,28]$. This synthetic pathway not only allows the polyol to gain hydroxyl groups but also allows the customization of polyols with different functionalities. Molecular masses, molecular mass distributions, linkage pathways, and the thermal stability of polyols were evaluated.

A series of water blown polyurethane flexible foams was prepared by greatly replacing conventional synthetic polyols with new bio-polyols from soybean and linseed oils. The influence of the new bio-polyols on the foam morphology (cellular structure, interconnectivity), density, mechanical, and thermal properties were studied as well. 


\section{Materials and Methods}

\subsection{General Considerations}

All bio-polyol syntheses were carried out on a double manifold Schlenk vacuum line under nitrogen atmosphere. Epoxidized linseed oil (ELO) with approximately 6.4 epoxy groups per triglyceride and $M_{\mathrm{n}}$ equal to $1182 \mathrm{~g} / \mathrm{mol}$, and epoxidized soybean oil (ESO) with approximately 4.3 epoxy groups per triglyceride and $M_{n}$ equal to $1168 \mathrm{~g} / \mathrm{mol}$, were supplied by Hallstar (Chicago, IL, USA) and Tecnosintesi Spa (Bergamo, Italy), respectively. Caprylic acid (CA, $\geq 99 \%$ ) and 3-phenyl butyric acid (3PBA, 99\%) were purchased from Carlo Erba (Milan, Italy). Partially bio-based diisocyanate (Tolonate ${ }^{\mathrm{TM}}$ X FLO 100) was kindly provided by Vencorex Chemicals (Saint-Priest, France). Niax Silicone L-537 XF (Momentive, NY, USA) was kindly supplied by Eigenmann and Veronelli SpA (Milan, Italy) and used as silicone surfactant. Polypropylene glycol (PPG, $M_{\mathrm{n}} \sim 3000 \mathrm{~g} / \mathrm{mol}$ ) was purchased from Merck KGaA (Darmstadt, Germany) and glycerol ( $\geq 99 \%)$ and triethylamine (TEA, 98\%) from Fisher Scientific Company (Hampton, NH, USA). Deuterated solvent, $\mathrm{CD}_{2} \mathrm{Cl}_{2}$, and hexamethyldisilane (HMDS) for NMR measurements were used as received from Merck KGaA (Darmstadt, Germany).

\subsection{Synthesis of Bio-Polyols in Presence of TEA}

Epoxidized oil (100 g) was placed in a three necked flask, equipped with a condenser. TEA ( $1 \%$ of epoxidized oil weight) was added to reaction flask and was stirred at $40{ }^{\circ} \mathrm{C}$ for $40 \mathrm{~min}$. Under continuous stirring, organic acid was added to the reactor dropwise ( $1 \mathrm{drop} / \mathrm{s})$ and the temperature of reaction was gradually raised. Finally, the vessel was put under vacuum for at least $40 \mathrm{~min}$ at $110{ }^{\circ} \mathrm{C}$. The epoxy/carboxyl ratio and reaction temperature were set according to data reported in Table 1.

Table 1. Properties of the bio-polyols.

\begin{tabular}{|c|c|c|c|c|c|c|c|c|c|c|}
\hline Run & $\begin{array}{c}\text { Epoxidized } \\
\text { Oil }^{1}\end{array}$ & Acid $^{2}$ & $\begin{array}{c}\text { Epoxy/ } \\
\text { Carboxyl } \\
\text { Ratio (eq) }\end{array}$ & TEA (wt \%) & $\mathrm{T}\left({ }^{\circ} \mathrm{C}\right)$ & $\begin{array}{c}t \\
(h)\end{array}$ & $\begin{array}{c}M_{\mathrm{n}}^{3} \\
(\mathrm{~g} / \mathrm{mol})\end{array}$ & $\mathrm{PDI}^{3}$ & $\begin{array}{c}\text { Acid } \\
\text { Number } \\
\text { (mg KOH/g) }\end{array}$ & $\begin{array}{c}\mathrm{OH} \\
\text { Number }^{5} \\
(\mathrm{mg} \mathrm{KOH} / \mathrm{g})\end{array}$ \\
\hline 1 & ESO & $\mathrm{CA}$ & $1 / 0.5$ & - & 170 & 16 & 2267 & 1.6 & 3 & 95 \\
\hline 2 & $\mathrm{ESO}$ & CA & $1 / 0.75$ & - & 170 & 16 & 2463 & 1.5 & 50 & 132 \\
\hline 3 & $\mathrm{ESO}$ & $\mathrm{CA}$ & $1 / 1$ & - & 170 & 16 & 2465 & 1.5 & 92 & 166 \\
\hline 4 & $\mathrm{ESO}$ & $\mathrm{CA}$ & $1 / 0.5$ & 1 & 170 & 16 & 1951 & 1.3 & 6 & 85 \\
\hline 5 & ESO & $\mathrm{CA}$ & $1 / 0.5$ & 1 & 130 & 16 & 1797 & 1.1 & 2 & 87 \\
\hline 6 & $\mathrm{ESO}$ & CA & $1 / 0.5$ & 1 & 110 & 6 & 1621 & 1.2 & 13 & 106 \\
\hline 7 & $\mathrm{ESO}$ & $\mathrm{CA}$ & $1 / 0.5$ & 1 & 150 & 6 & 1776 & 1.2 & 15 & 83 \\
\hline 8 & ELO & $\mathrm{CA}$ & $1 / 0.5$ & 1 & 150 & 4 & 1769 & 1.4 & 3 & 67 \\
\hline 9 & $\mathrm{ESO}$ & 3PBA & $1 / 0.5$ & - & 150 & 16 & 2400 & 1.6 & 37 & 101 \\
\hline 10 & $\mathrm{ESO}$ & 3PBA & $1 / 0.5$ & 1 & 110 & 16 & 1869 & 1.1 & 20 & 93 \\
\hline 11 & ELO & 3PBA & $1 / 0.5$ & 1 & 130 & 4 & 2079 & 1.2 & 15 & 88 \\
\hline
\end{tabular}

${ }^{1} \mathrm{ESO}=$ epoxidized soybean oil, ELO = epoxidized linseed oil; ${ }^{2} \mathrm{CA}=$ caprylic acid, 3 PBA $=3$-phenyl-butyric acid; ${ }^{3} M_{\mathrm{n}}=$ number-average molecular weight and PDI = polydispersity index determined by SEC using polystyrene standards and calculated on the whole distribution of oligomers; ${ }^{4}$ Determined according to IUPAC 2.201 standard method; ${ }^{5}$ Determined according to ASTM D 4274.

\subsection{Preparation of PU Foams via Prepolymer Synthesis}

PU intermediates were synthesized in a closed vessel at atmospheric pressure under mechanical stirring. Quasi-prepolymers [29] were prepared by first reacting a large excess of a isocyanate (free isocyanate content about $30 \mathrm{wt} \%$ ) with PPG for $40 \mathrm{~min}$ in the presence of dibutyltin dilaurate $(0.01 \mathrm{wt} \%)$ and silicone surfactant $(0.5 \mathrm{wt} \%)$, then afterwards the isocyanate-terminated intermediate, that was formed in the previous step, was reacted with bio-polyol adding again a small amount of catalyst $(0.01 \mathrm{wt} \%)$. The ratio between PPG and bio-based polyol is 1:2.

PU foams (PUFs) were prepared mixing the PU prepolymer, in a pre-heated container, with catalyst, silicone surfactant, glycerol, and diisocyanate by mechanical stirrer at $1400 \mathrm{rpm}$ for $25 \mathrm{~s}$. Distilled water (1.5 wt \%) was used as blowing agent. An isocyanate index, that is the excess of isocyanate over the theoretical amount for 1:1 reaction with all 
active hydrogen-bearing groups expressed in percentage terms, equal to 100 was reached. The expanded PUFs were crushed after foaming and then cured for $2 \mathrm{~h}$ in an oven at $60^{\circ} \mathrm{C}$.

\subsection{Characterization Techniques}

The hydroxyl number $(\mathrm{OH}$ number, $\mathrm{mg} \mathrm{KOH} / \mathrm{g}$ ) of the polyol was determined by the imidazole-catalyzed pyromellitic dianhydride method, according to ASTM D 4274-99. The acid value was determined according to IUPAC 2.201 standard using the indicator method.

${ }^{13} \mathrm{C}-\mathrm{NMR}$ spectroscopic analysis of the polyols was carried out on a Bruker (Billerica, MA, USA) Avance $400 \mathrm{MHz}$ NMR spectrometer in $\mathrm{CD}_{2} \mathrm{Cl}_{2}$ at $25^{\circ} \mathrm{C}$. HMDS signal was used as internal reference.

Size exclusion chromatography (SEC) analyses were performed on a Waters (Milford, MA, USA) GPCV2000 system, using THF as mobile phase, at $35^{\circ} \mathrm{C}$ with a $0.6 \mathrm{~mL} / \mathrm{min}$ flow. Sample concentration was set at $2 \mathrm{mg} / \mathrm{mL}$ and injection volume at $150 \mu \mathrm{L}$. The SEC system was calibrated using polystyrene standards.

FTIR spectra were recorded using a PerkinElmer (Waltham, MA, USA) Spectrum Two spectrometer from 4000 to $550 \mathrm{~cm}^{-1}$ with a wavenumber resolution of $4 \mathrm{~cm}^{-1}$ in total attenuated reflectance (ATR) mode.

Thermogravimetric analysis (TGA) was performed on a PerkinElmer (Waltham, MA, USA) TGA 7 instrument at a scan rate of $20^{\circ} \mathrm{C} / \mathrm{min}$ under nitrogen atmosphere. TGA and derivate thermogravimetry (DTG) curves were recorded from 50 up to $750{ }^{\circ} \mathrm{C}$.

The viscosity of the polyol was measured using a TA Instruments (New Castle, DE, USA) AR 2000 dynamic stress rheometer at $20^{\circ} \mathrm{C}$ with a flow test in the shear rate range between 0.01 and $1000 \mathrm{~s}^{-1}$. The rheometer was equipped with a plate and steel cone (diameter of $20 \mathrm{~mm}$, angle of $0.5^{\circ}$ and truncation gap of $16 \mu \mathrm{m}$ ).

The cream time and free rise time of PUFs were evaluated according to the standard "cup-test" in ASTM D7487-13E1 using a digital timer. Each test was conducted repeatedly at least five times to minimize experimental error.

A stereo microscope model Solomark-Science (Yuyao, China) Lab 3D Scope equipped with a digital camera was used to characterize the morphology of foams. The apparent density of foam samples was measured according to EN ISO 845:2006.

Mechanical properties of the foams were analyzed through compression force deflection tests performed by a Zwick-Roell (Ulm, Germany) Z010 mechanical testing machine with a load cell of $2.5 \mathrm{kN}$. Cylindrical-shape specimens (height of $25 \mathrm{~mm}$ and diameter of $50 \mathrm{~mm}$ ) were firstly pre-compressed twice to $75 \%$ of their initial height at $250 \mathrm{~mm} / \mathrm{min}$.

After a rest of $6 \mathrm{~min}$, the height of each specimen was determined applying a load of $140 \mathrm{~Pa}$. Finally, the specimens were compressed to $50 \%$ of their height at $50 \mathrm{~mm} / \mathrm{min}$ and the final load after $60 \mathrm{~s}$ was recorded. Reported data were averaged on three tests per sample.

\section{Results and Discussion}

\subsection{Synthesis of Bio-Polyols}

Renewable bio-polyols with several functionalization degrees were prepared from two different no-food vegetable epoxidized oils coming from soybean (ESO) and linseed (ELO) oil, with approximately 4.3 and 6.4 epoxy per triglyceride, respectively.

Bio-based polyols were developed using an environmentally friendly, solvent-free method in which no purification or separation steps are required (Scheme 1). Two structurally different organic acids, caprylic and 3-phenylbutyric acid, respectively, were chosen to analyze the effect of an aliphatic short linear chain or the presence of an aromatic motive on PU formulation and properties. 


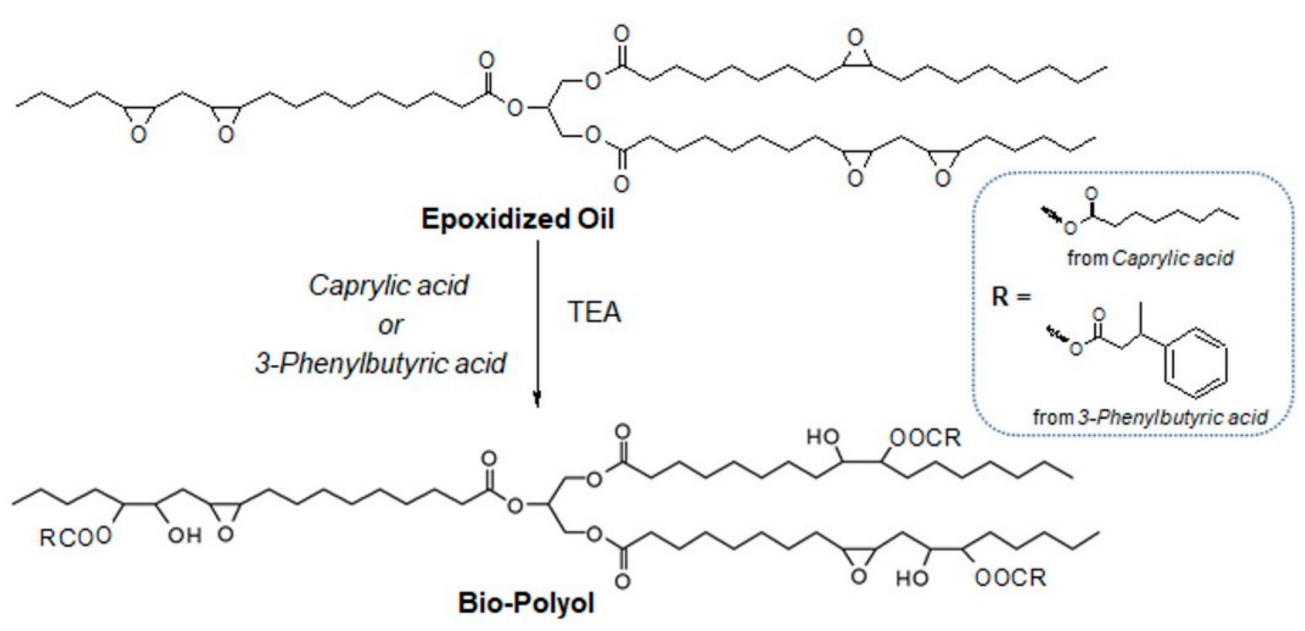

Scheme 1. Schematic representation of the synthesis of bio-polyols in the presence of catalyst.

It is worth noting that the hydroxyl functionality of bio-polyols is a well-known key issue for the synthesis of PUFs. With a complete conversion of epoxide group per triglyceride, a maximum total number of $\mathrm{OH}$ groups was estimated around 4-6. However, with these high functionalities, rigid foams are expected [29-31]. A fine tuning of the reaction conditions in polyols synthesis could provide polyols with relatively high hydroxyl equivalent weight, attractive for the synthesis of flexible PUFs. For our purpose, a medium functionality value of around 3 along with a hydroxyl number up to around $90 \mathrm{mg} \mathrm{KOH} / \mathrm{g}$ were the targets.

The effects of the epoxy/carboxyl ratio, reaction time, and reaction temperature on the final polyols' structure and functionalities were investigated (Table 1). The reactions were conducted both in the presence and in the absence of TEA, a Lewis base catalyst. ESO and ELO present several internal epoxy groups, thus the ring-opening reactions are more difficult than in structures with terminal epoxy groups, due to their steric hindrance.

TEA was chosen to facilitate the ring-opening of the internal epoxy groups of the epoxidized oil, while preserving other functional groups of the epoxidized oil, such as triglyceride ester skeletons. Moreover, this catalyst is a well-known catalyst to produce PUFs, thus it is not necessary to remove it after the first step, making this approach both time- and cost-effective.

TEA was also evaluated to minimize the formation of cross-linked structures to produce less viscous and more processable polyols with narrower polydispersity indices that are more suitable for flexible polyurethane foam synthesis. A similar approach was reported in the literature [18] by using DBU as catalyst for the ring-opening reaction and subsequent preparation of polyurethanes.

A careful screening was conducted with ESO and caprylic acid without catalyst (runs 1-3) at $170{ }^{\circ} \mathrm{C}$ for $16 \mathrm{~h}$ at different epoxy/carboxyl ratios.

The ${ }^{13} \mathrm{C}$-NMR spectra are shown in Figure 1. This figure shows the region ranging from 84 to $53 \mathrm{ppm}$; this spectral window was chosen because it is diagnostic of the presence of the resonances of $d$ and $e$ carbon atoms assigned to epoxy group, in the figure at $56.5-55.0 \mathrm{ppm}$, and of $f, g, h$ and $i$ carbon atoms in $\alpha$ position to the secondary hydroxyl group and the ester group (81.5-71.0 ppm). Moreover, in this region, resonances at 67.4 and $60.5 \mathrm{ppm}$ are easily assigned to methine and methylene carbon atoms of glycerol, labelled as $a$ and $b$ carbon atoms, respectively. Only the polyol obtained at epoxy/carboxyl ratio equal to 1:0.5 shows resonances assigned to residual epoxy groups in the region from 55.0 to $56.5 \mathrm{ppm}$, thus a full conversion of epoxide groups into ester and hydroxyl groups was not achieved at low acid concentration. At increasing acid concentrations, resonances assigned to methylene carbon atoms linked to the hydroxyl group and ester group become preponderant. At high acid concentrations (runs 2 and 3), resonances at 177-178 ppm (not shown) can be assigned to the presence of unreacted caprylic acid in the end product. The 
${ }^{13} \mathrm{C}-\mathrm{NMR}$ analysis showed that at a decreasing epoxy/carboxyl ratio, a more extensive grafting of caprylic acid on oil backbone is achieved.

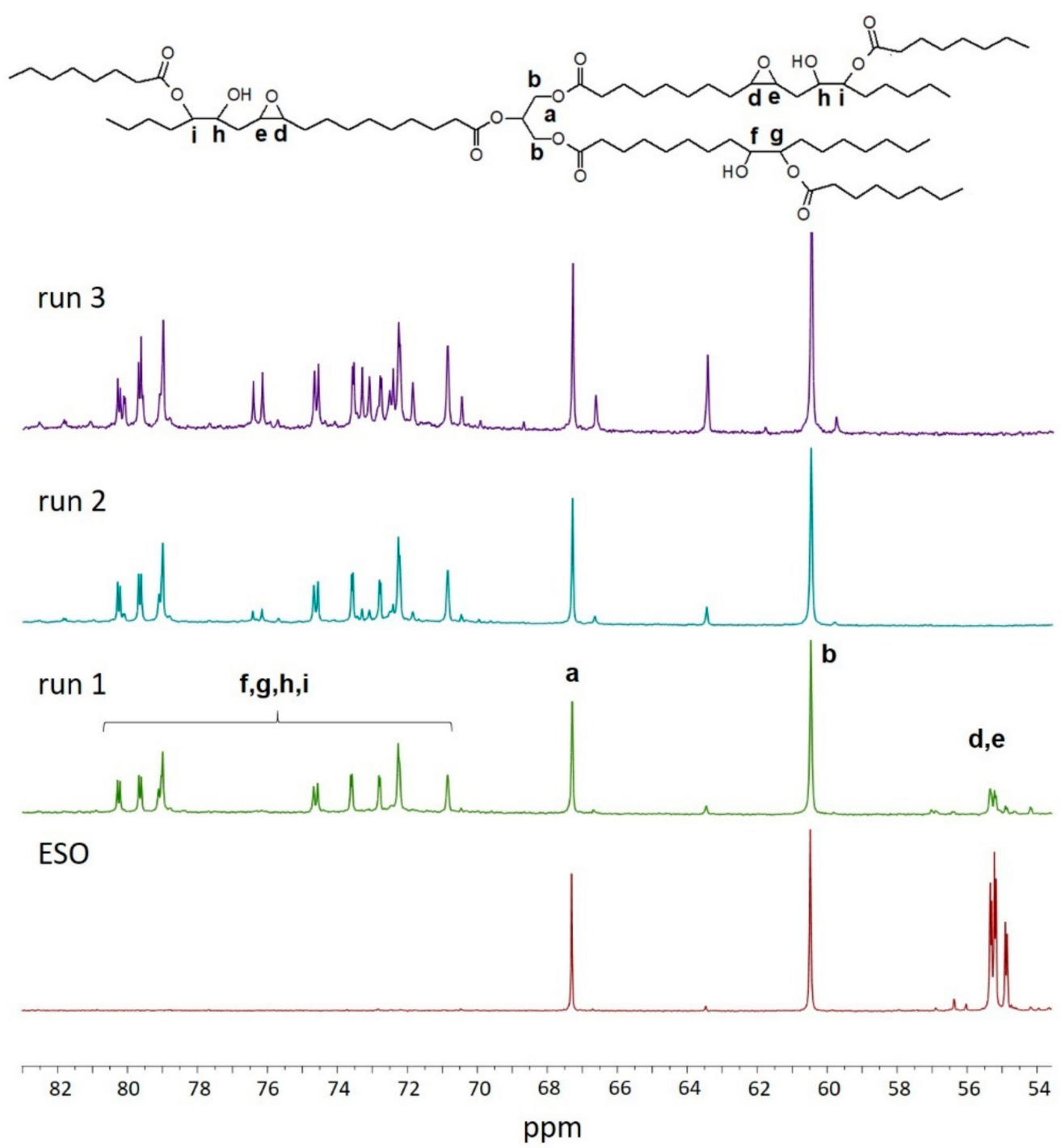

Figure 1. ${ }^{13} \mathrm{C}$-NMR spectrum of bio-polyol from ESO (epoxidized soybean oil) and caprylic acid obtained at different epoxy/carboxyl molar ratios. Signals are normalized in respect to signals at 67.3 and $60.5 \mathrm{ppm}$ (methylene and methine carbon atoms of glycerol).

In general, comparable molecular weights were achieved (Table 1). The SEC curves as function of molecular weight (MW) in Figure 2 show, for all the samples, a main fraction, whose molecular weight depends on the functionalization degree of epoxidized oil, and minor fractions at higher molecular weight which can be ascribed to by-products with a variable number of grafted side chains (Figure 2a). This oligomeric fraction, present in all the polyols at about $3800-5400$ and $6500-7000 \mathrm{~g} / \mathrm{mol}$, corresponds to trimers and tetramers respectively, with an ester functionalization degree between 2-3 per oil molecule. 

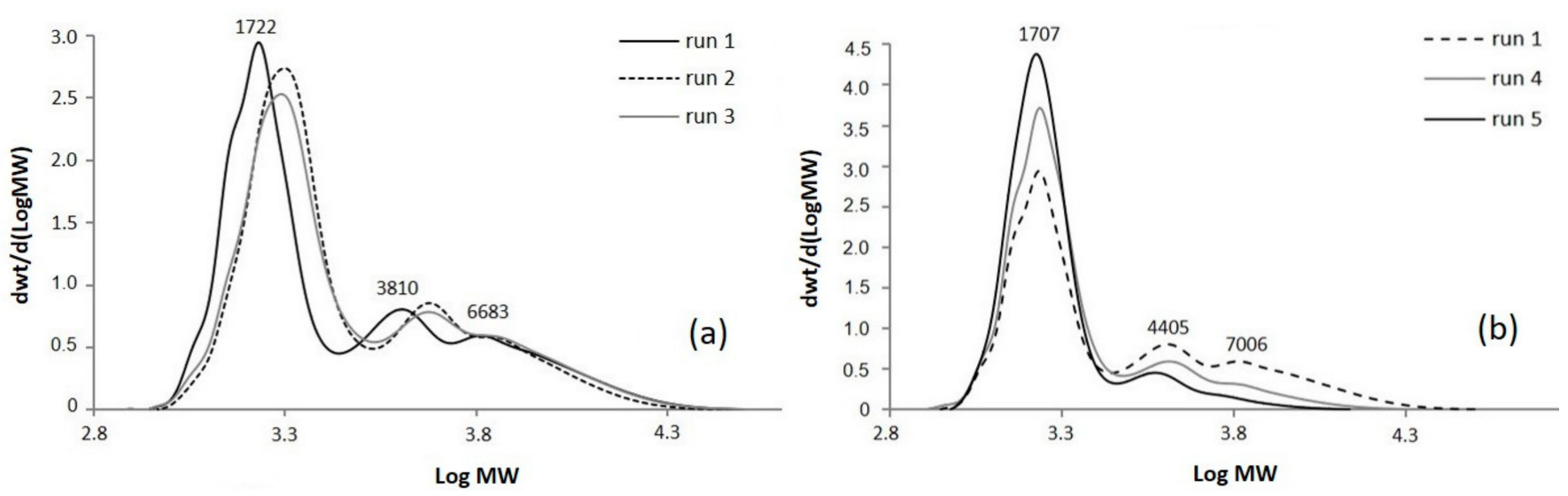

Figure 2. SEC (size exclusion chromatography) chromatograms of bio-polyols from ESO and caprylic acid: (a) with different epoxy/carboxyl ratio and (b) effect of the presence of TEA (triethylamine) on molecular weight.

A low epoxy/carboxyl ratio does not avoid the cross-linking side reactions that lead to increased $\mathrm{OH}$ functionality and concurrently lead to residual unreacted acid in polyols reaching up to $13 \%$ (ratio 1:0.75) and $23 \%$ (ratio $1: 1$ ) as it is estimated from acid numbers reported in Table 1 (runs 2 and 3). Moreover, the excess of unreacted acid should be reduced for obtaining consistent polyurethane foams.

At a 1:0.5 epoxy/carboxyl ratio, some reactions have been conducted with TEA as catalyst (runs 4-7) and the corresponding SEC chromatograms are shown in Figure $2 b$ and Figure S1 Supplementary Materials. The SEC curve of run 4 highlights a narrower molecular weight distribution with a decrease of the oligomerization peaks $\left(M_{\mathrm{W}}\right.$ at 4405 and $7006 \mathrm{~g} / \mathrm{mol}$, respectively) when compared to reference run 1, carried out in the same experimental conditions (Figure $2 b$ ). This can be explained by the fact that TEA hinders ringopening by hydroxyl groups, limiting oligomerization. When the reaction was conducted in presence of TEA at reduced temperature $\left(130^{\circ} \mathrm{C}\right.$, run 5$), 87 \mathrm{wt} \%$ of no-oligomerized oil was achieved, with only the $10 \mathrm{wt} \%$ of the trimer. These results point out how the presence of TEA strongly influences the ring-opening and cross-linking reactions, disfavoring the formation of the oligomers. Moreover, when TEA is used, the reactions can be carried out at low temperatures obtaining an $\mathrm{OH}$ number around $87 \mathrm{mg} \mathrm{KOH} / \mathrm{g}$, comparable with that obtained at $170{ }^{\circ} \mathrm{C}$ (run 5 and run 4).

Reducing the reaction time from 16 to $6 \mathrm{~h}$ and running at $110^{\circ} \mathrm{C}$ (run 6), a less extensive ring-opening reaction was achieved than run 5 , as shown by shoulder due to unreacted vegetable oil $\left(M_{\mathrm{W}}\right.$ corresponding about to $1200 \mathrm{~g} / \mathrm{mol}$ ) (see Figure S1 Supplementary Materials). Moreover, the low reaction temperature did not avoid the formation of a significant oligomeric fraction which consists of about four oil molecules $(19 \%$ of total chromatogram area). The high hydroxyl number, recorded for run 6, could be explained by side reactions that lead to increase - $\mathrm{OH}$ functionality.

Finally, ESO and caprylic acid were reacted at $150{ }^{\circ} \mathrm{C}$ for $6 \mathrm{~h}$ (run 7) obtaining an adequate end product. Nevertheless, evaluating the residual acid value, the $\mathrm{OH}$ number, the molecular weight, and the polydispersity index, the best bio-polyol from ESO and caprylic acid resulted from run 5, carried out at $130^{\circ} \mathrm{C}$ for $6 \mathrm{~h}$, at 1:0.5 epoxy/carboxyl molar ratio and in the presence of TEA.

3-Phenyl butyric acid was used to study the effect of aromatic moieties of bio-polyols on the PUF synthesis, properties, and structure. The reactions with ESO were first conducted at $150{ }^{\circ} \mathrm{C}$ (run 9) then afterwards adopting milder temperature $\left(110{ }^{\circ} \mathrm{C}\right)$ in the presence of TEA $(1 \mathrm{wt} \%)$. As can be observed in Figure 3, the presence of TEA along with a mild temperature leads to a better control of PDI (1.1 vs 1.6 when TEA is absent) and to lower amount of oligomers. The first oligomeric faction whose molecular weight corresponds to $3970 \mathrm{~g} / \mathrm{mol}$ was ascribed to low substituted trimer (or to high substituted dimer) of soybean oil; it was about $12 \%$ of total chromatogram area for run 10 . The second oligomeric faction for run 10, whose molecular weight corresponds to $6150 \mathrm{~g} / \mathrm{mol}$, was 
only $2 \%$ of total chromatogram area, was ascribed to the trimer of soybean oil with 2.5 acid molecules grafted per soybean oil unit.

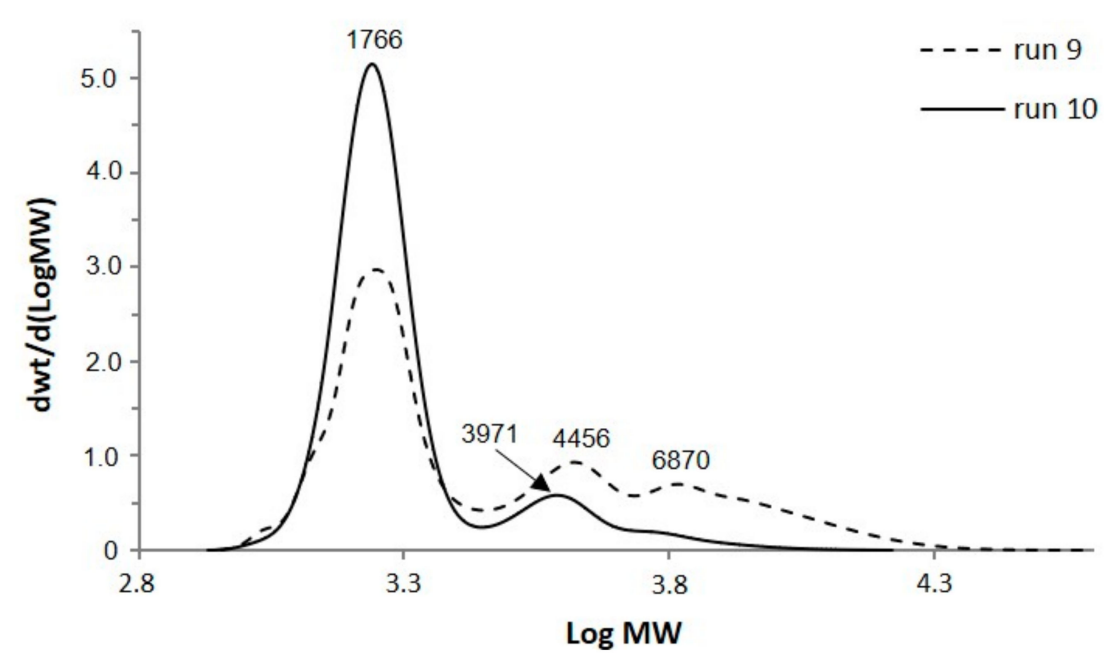

Figure 3. SEC chromatograms of bio-polyols from ESO and 3-phenyl butyric acid.

As already observed for bio-polyols from ESO and CA, the reactions conducted at low temperature in the presence of TEA lead to $\mathrm{OH}$ values in the desired range.

Finally, two reactions were carried out using ELO (run 8 and 11 in Table 1). Some preliminary trials performed at $150{ }^{\circ} \mathrm{C}$ overnight with different epoxy/carboxyl ratios (from 0.5:1 to 2:1) showed that this epoxidized oil tends to favor side reactions in comparison with ESO leading to more extensive oligomerization and consequently, higher molecular weights and polydispersity indices. Thus, this higher reactivity of ELO towards the self-polymerization was partially balanced with a short reaction time $(4 \mathrm{~h})$ and low temperatures, $150^{\circ} \mathrm{C}$ for $\mathrm{CA}$ and $130^{\circ} \mathrm{C}$ for $3 \mathrm{PBA}$, giving rise to $20 \%$ of oligomer content in the bio-polyols from ELO. Furthermore, in this case, the 1:0.5 epoxy/carboxyl ratio represents the most promising conditions to balance the functionalization degree and amount of unreacted acid in the end product.

${ }^{13} \mathrm{C}-\mathrm{NMR}$ analysis clearly shows the grafting of caprylic and 3-phenyl butyric acid on the ELO and ESO backbone due to the presence of the characteristic resonance belonging to carbon atoms in $\alpha$ position to the secondary hydroxyl group and the ester group (see Figures S2-S4 Supplementary Materials). Herein, the ${ }^{13} \mathrm{C}-\mathrm{NMR}$ spectrum of bio-polyol from ELO and 3-phenyl butyric acid is shown in Figure 4. The assignment was conducted according to the literature [32] and by comparing the spectrum with those of the epoxidized oil and of the corresponding organic acid.

Typical resonances of the glycerol structure can be easily assigned: the methine carbon atom labelled as $a$ is observed at $69.1 \mathrm{ppm}$, the methylene carbon atoms in $\alpha$ position with respect to the methine (carbon $b$ ) appear at $61.9 \mathrm{ppm}$, while carbon $c$ of the carboxylic acid group falls in the region from 171.1 and $171.6 \mathrm{ppm}$. The methylene groups showed chemical shifts in the range between $\delta 21.0-36.00 \mathrm{ppm}$, due to adjacent groups' effect, and their position with respect to each functional group. Resonances from 12.20 to $8.0 \mathrm{ppm}$ are observed and assigned to the carbon atoms of the methyl groups of the main chain.

Carbon atoms labelled as $\mathrm{A}^{\prime}, \mathrm{C}^{\prime}, \mathrm{F}^{\prime}$ and $\mathrm{B}^{\prime}, \mathrm{D}^{\prime}, \mathrm{E}^{\prime}$ in $\alpha$ position to the secondary hydroxyl group and the ester group, respectively, showed resonances in the region ranging from 81.5 to $71.0 \mathrm{ppm}$. The residual epoxy groups showed resonances in the region from 55.0 to $56.5 \mathrm{ppm}$, thus confirming the partial conversion of epoxy group, in line with the results from alcohol titration. 

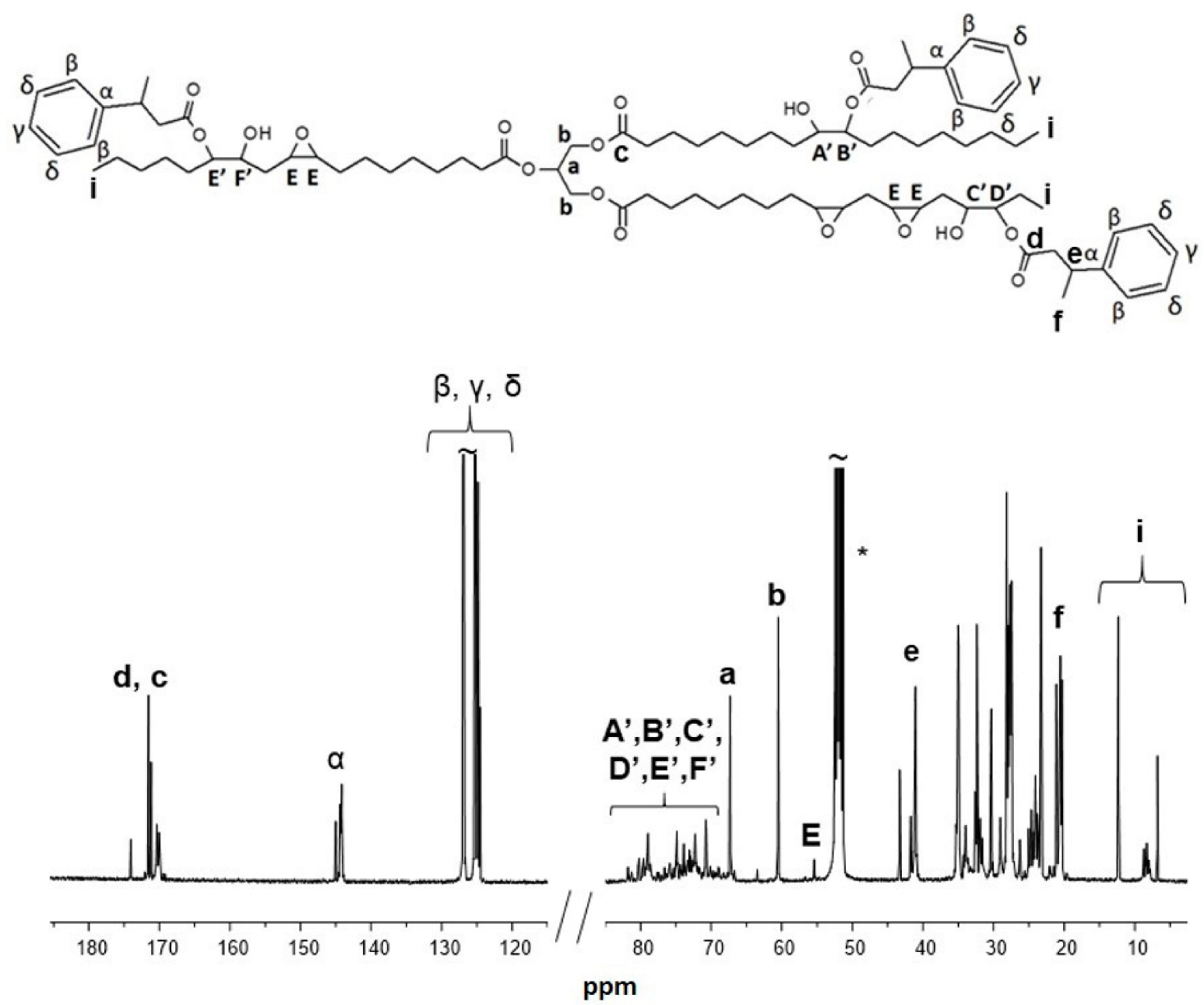

Figure 4. ${ }^{13} \mathrm{C}-\mathrm{NMR}$ spectrum of bio-polyol from ELO (epoxidized linseed oil) and 3-phenyl butyric acid (run 11 in Table 1).

* $\mathrm{CD}_{2} \mathrm{Cl}_{2}$ was used as solvent.

The carbon atoms of the aromatic moieties showed typical resonances in the region from 124.0 to $127.0 \mathrm{ppm}$ (carbon atoms labelled as $\beta, \delta$ and $\gamma$ ) and at $144 \mathrm{ppm}$ for carbon $\alpha$. The carbon atoms of the carboxyl acid group from the aromatic linkers (d) showed a resonance signal at $\delta 170 \mathrm{ppm}$, in the same region of carbon c.

As mentioned above, a medium functionality value of about 3 along with a hydroxyl number up to $93 \mathrm{mg} \mathrm{KOH} / \mathrm{g}$ were considered suitable to prepare polyurethane prepolymers. Moreover, the 1:0.5 epoxy/CA ratio seemed the most promising compromise for obtaining this functionalization degree with a negligible amount of unreacted acid. Thus, bio-polyols obtained from run 5, 10, 8, and 11 with hydroxyl number ranging from 67 to 93 were chosen to prepare PU foams.

The complete characterization of the chosen bio-polyols is reported in Table 2.

Table 2. Properties of selected bio-polyols.

\begin{tabular}{|c|c|c|c|c|c|c|c|}
\hline Run & $\begin{array}{c}\text { Bio-Polyol } \\
\text { Composition }\end{array}$ & Viscosity $^{2}$ (Pa-s) & $\begin{array}{c}M_{\mathrm{n}}{ }^{3} \\
(\mathrm{~g} / \mathrm{mol})\end{array}$ & PDI $^{3}$ & $\begin{array}{c}\text { Acid } \\
\text { Number } 4 \\
(\mathrm{mg} \mathrm{KOH} / \mathrm{g})\end{array}$ & $\begin{array}{c}\text { OH } \\
\text { Number }^{5} \\
(\mathrm{mg} \mathrm{KOH} / g)\end{array}$ & $\begin{array}{c}\text { OH } \\
\text { Functionality }\end{array}$ \\
\hline 5 & $\mathrm{ESO}, \mathrm{CA}$ & 3.03 & 1797 & 1.15 & 2 & 87 & 2.8 \\
\hline 8 & $\mathrm{ELO}, \mathrm{CA}$ & 4.70 & 1769 & 1.36 & 3 & 67 & 2.1 \\
\hline 10 & ESO, 3PBA & 24.26 & 1869 & 1.31 & 20 & 93 & 3.1 \\
\hline 11 & ELO, 3PBA & 470.3 & 2079 & 1.22 & 15 & 88 & 3.3 \\
\hline
\end{tabular}

${ }^{1}$ ESO = epoxidized soybean oil, CA = caprylic acid, ELO = epoxidized linseed oil, 3PBA = 3-phenyl butyric acid; epoxy/carboxyl ratio $=1: 0.5 ;{ }^{2}$ Measured at $20{ }^{\circ} \mathrm{C} ;{ }^{3}$ Determined by SEC using polystyrene standards; ${ }^{4}$ Determined according to IUPAC 2.201 standard method; ${ }^{5}$ Determined according to ASTM D $4274 ;{ }^{6}$ Calculated by the formula: $M_{n}{ }^{*} \mathrm{OH}_{\text {number }} /(56.1 * 1000)$. 
The acid content in all bio-polyols was below $20 \mathrm{mg} \mathrm{KOH} / \mathrm{g}$ confirming organic acid grafting on vegetable oil backbone. Lower acid values (2-3 mg KOH/g) were observed for bio-polyols from caprylic acid with respect to those observed for bio-polyols from 3-phenyl butyric acid with acid value between 15-20 mg KOH/mg, corresponding to maximum $10 \mathrm{wt} \%$ of unreacted acid in end product. It is worth noting that these residual acidities did not interfere with the polyurethane synthesis.

Moreover, it was found that polyol from run 8 had the lowest $\mathrm{OH}$ functionality although the low acid number demonstrated almost complete caprylic acid grafting on the vegetable oil backbone. However, a portion of oil was not converted into polyol as shown by the shoulder corresponding to $1200 \mathrm{~g} / \mathrm{mol}$ in SEC chromatogram of run 8 (see Figure S5 Supplementary Materials).

In general, the viscosity of bio-polyols is correlated with the number of cross-linked structures and unreacted acid [19]. Furthermore, the side chains linked to the backbone of the polyols influence the rheological behavior as well. All the characterized bio-polyols showed a behavior typical of Newtonian fluids exhibiting a constant viscosity in the whole range of strain rates investigated (see Figure S6 Supplementary Materials). The introduction of aromatic moieties from 3-phenyl butyric acid leads to an increase in viscosity (run 10 and 11 in Table 2) since the presence of the aromatic ring increases the rigidity of the sidechain and the intermolecular friction resistance [33]. In particular, the viscosity of these bio-polyols increases by one and two orders of magnitude, respectively when compared with that of polyols from caprylic acid. These enhancements in viscosity could be related to the different molecular weight distributions between run 10 and 11 [34]. In fact, observing the SEC chromatograms of both samples it emerges that the fraction corresponding to $3900-4100 \mathrm{~g} / \mathrm{mol}$ represents $16 \%$ and $12 \%$ for run 11 and 10 , respectively. The main fraction in run 11 corresponds to higher molecular weight (about $1900 \mathrm{~g} / \mathrm{mol}$ ) than in run 10 (1750 g/mol), (see Figure S5 Supplementary Materials), arising from more extensive functionalization by organic acid, according to $\mathrm{OH}$ titration (Table 2). At the same time, the functionalization of oil could involve multiple adjacent sites on the same aliphatic chain in linseed oil, that contains a larger amount of linolenic acid (50-55\%) than in soybean oil chain $(13 \%)[35,36]$. This could increase the viscosity due to steric hindrance, arising from packed aromatic substituents on the same side chain of oil, limiting the molecules flow for the bio-polyol obtained from run 11.

The FTIR spectra of the selected bio-polyols for PU synthesis are presented in Figure 5. The broad absorption peak between $3600-3200 \mathrm{~cm}^{-1}$ for all spectra is characteristic for stretching vibrations of $\mathrm{OH}$ groups, $\mathrm{C}=\mathrm{O}$ stretching vibration of esters at $1738-1732 \mathrm{~cm}^{-1}$, and $-\mathrm{CH}_{2}$ symmetric and asymmetric stretching at 2924 and $2854 \mathrm{~cm}^{-1}$, respectively [18]. The oxirane ring vibration peak at $824 \mathrm{~cm}^{-1}$ of epoxidized vegetable oils was weakly present according to ${ }^{13} \mathrm{C}-\mathrm{NMR}$ analysis. Moreover, polyols from 10 and 11 runs showed typical absorption peaks of $\mathrm{C}-\mathrm{H}$ stretching at $3009-3088 \mathrm{~cm}^{-1}, \mathrm{C}=\mathrm{C}$ stretching at $1585-1603 \mathrm{~cm}^{-1}$ and $=\mathrm{C}-\mathrm{H}$ bending at 699 and $762 \mathrm{~cm}^{-1}$ of monosubstituted aromatic groups from 3-phenyl butyric acid.

Figure $6 a, b$ show the TGA and DTG thermograms of the selected bio-polyols, respectively. The samples prepared from CA exhibit a good thermal stability and a temperature of degradation at $5 \%$ mass loss over $300{ }^{\circ} \mathrm{C}$. Regarding the samples prepared from 3PBA, a first degradation with a loss mass between $8 \%$ and $10 \%$ attributed to the presence of unreacted acid at lower temperature is well highlighted by a DTG peak centered at about $170{ }^{\circ} \mathrm{C}$. The main degradation process of the bio-polyols takes place between 300 and 500 ${ }^{\circ} \mathrm{C}$ with a corresponding DTG peak centered at ca. $400{ }^{\circ} \mathrm{C}$ for each sample. Moreover, all the analyzed polyols present a residual mass at $700{ }^{\circ} \mathrm{C}$ in nitrogen approximately of $1 \%$. 


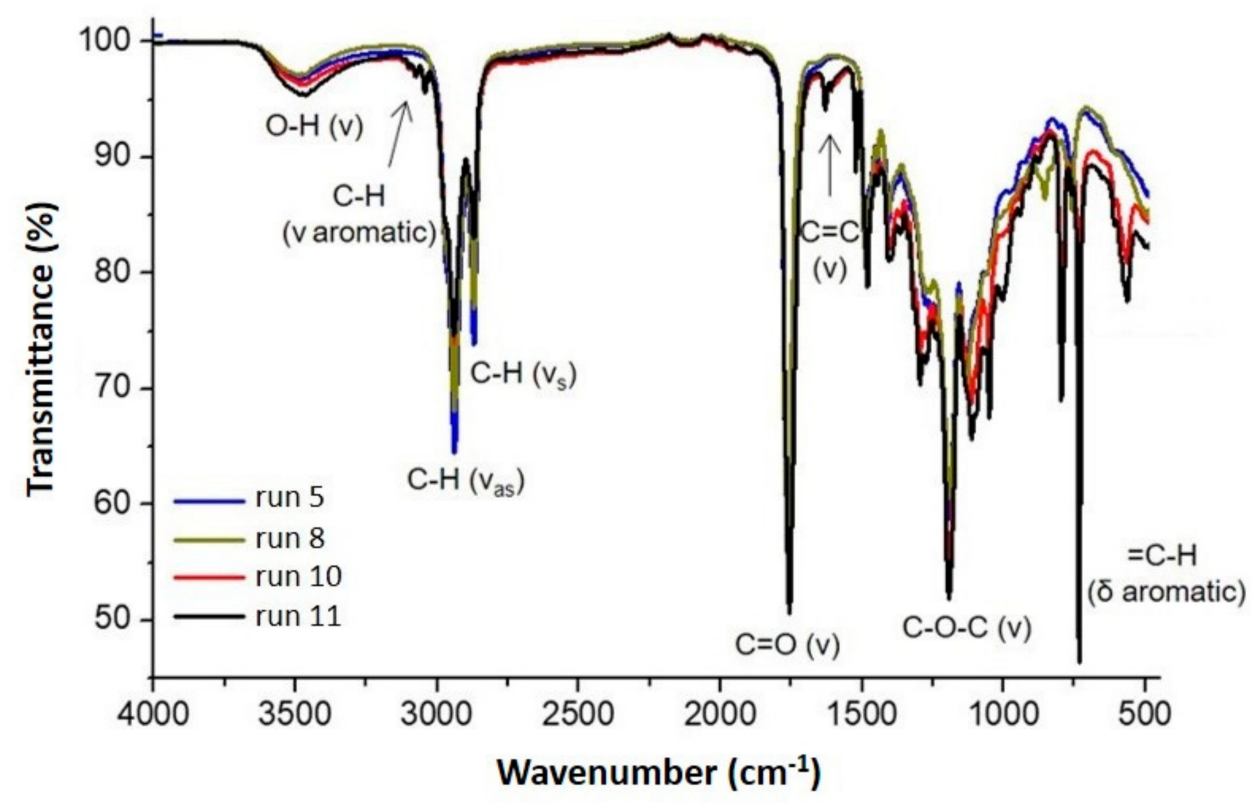

Figure 5. FTIR spectra of the selected bio-polyols from CA (caprylic acid; run 5, 8) and 3PBA (3-phenyl butyric acid; run 10, 11).
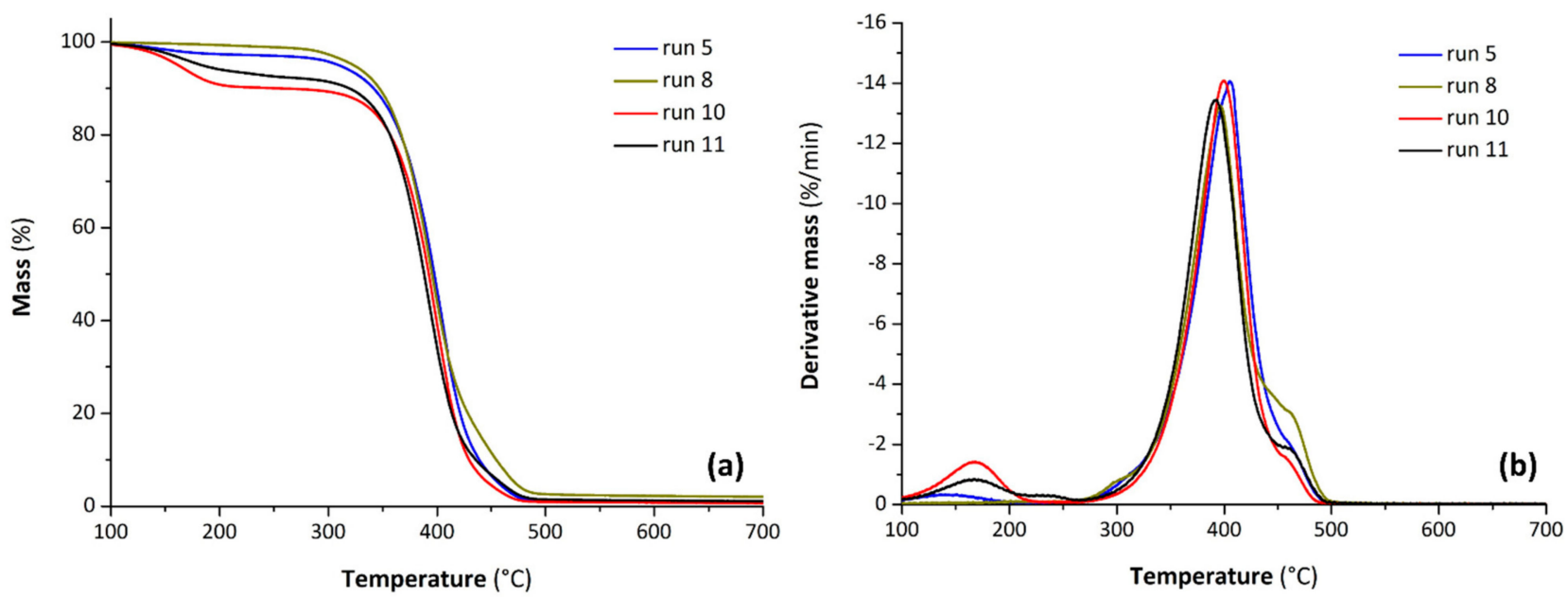

Figure 6. TGA (thermogravimetric analysis) (a) and DTG (derivate thermogravimetry) (b) curves for selected bio-polyols from CA (run 5, 8) and 3PBA (run 10, 11).

\subsection{PU Foam Development and Formulation Optimization}

For the synthesis of polyurethane foams, a PU quasi-prepolymer was synthesized by a two-step reaction (Scheme 2). The first step involves the reaction between the polypropylene glycol and a large excess of diisocyanate, giving an isocyanate-terminated intermediate. The second step consists of the reaction of the bio-polyol with the isocyanate-terminated intermediate giving an isocyanate-terminated quasi-prepolymer. 
<smiles>CC(CC(C)(O)C(C)(C)C)OC(C)(C)C</smiles>

PPG
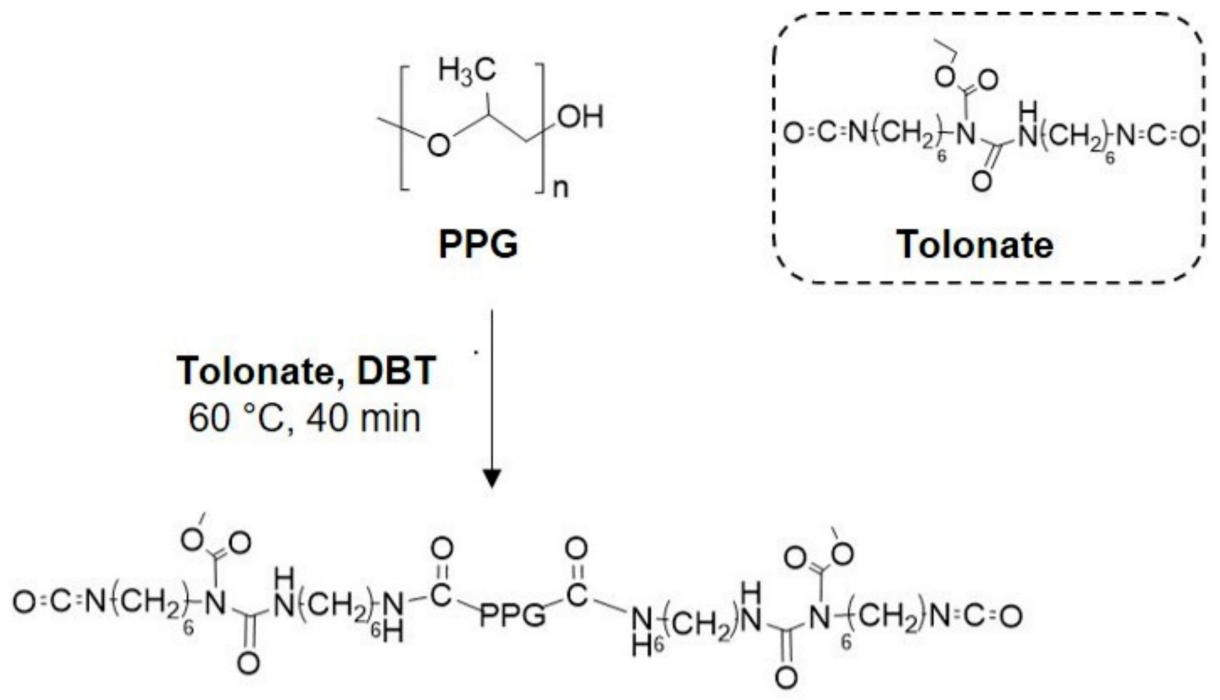

Isocyanate-terminated intermediate

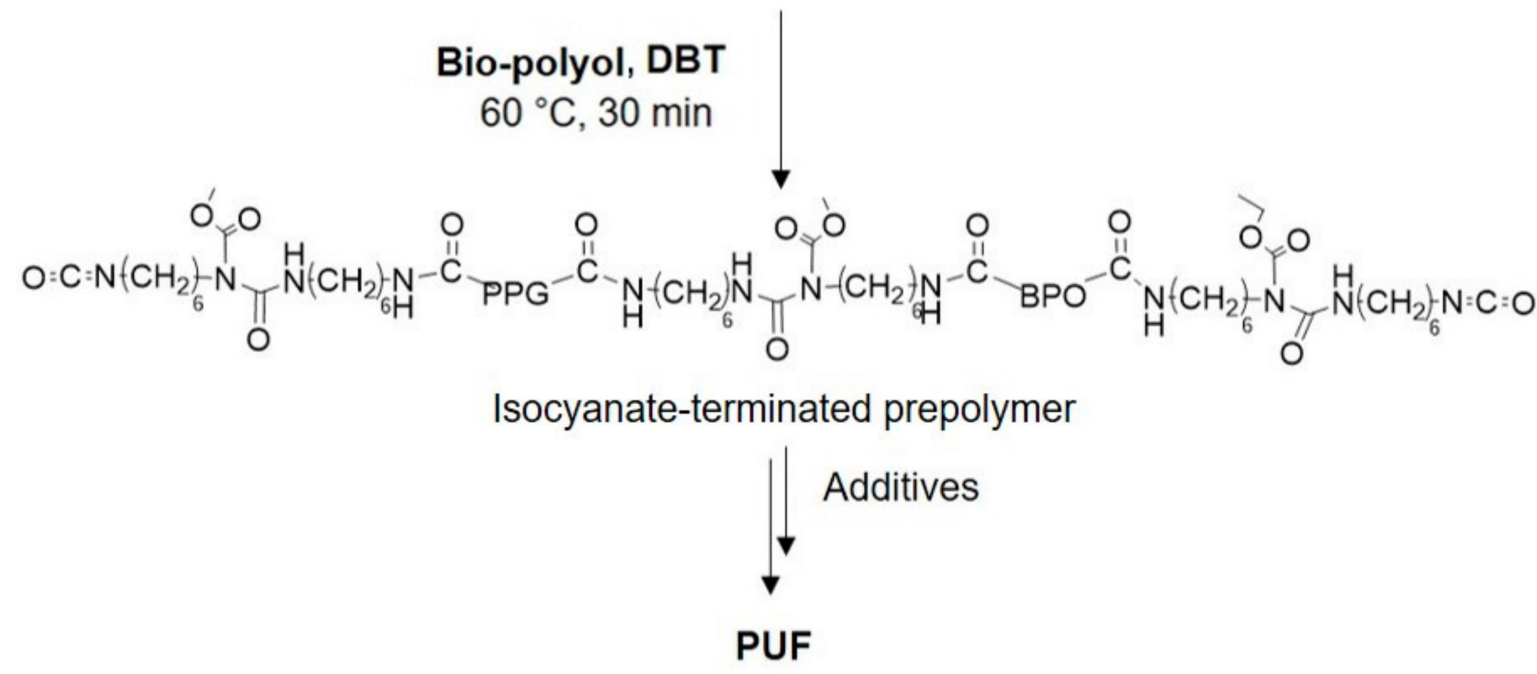

Scheme 2. Schematic representation of synthetic routes to prepare foams.

These prepolymers were reacted with some additives to obtain the final PUFs. Representative photos of prepared foams are shown in Figure S7 (Supplementary Materials).

To prepare bio-based PU foams, a polyol from fossil source (PPG) was used in mixture with the synthesized bio-polyols (bio-polyols/PPG weight ratio 2:1) and the silicon surfactant, thus forming a stable emulsion with low water amount. Distilled water was used as chemical blowing agent, and its content kept constant, at $1.5 \mathrm{wt} \%$ for all formulations. This amount was chosen because water content would impact both bio-stability of mixtures containing plant-oil-based prepolymer and the chemical composition of the PU foam polymer matrix. A small amount of glycerol $(3 \mathrm{wt} \%)$ was used to enhance the bio-polyol miscibility with water. The formulations were labeled as Tolo $x$ where $x$ corresponds to the number of the selected bio-polyol. A reference sample (Tolo ref in Table 3) was prepared by using the polyol from fossil sources (PPG) and the same additives. 
Table 3. Formulation of the foams used in this study.

\begin{tabular}{ccc}
\hline & Tolo $\mathbf{x}$ & Tolo Ref \\
\hline Bio-polyol & 67 & 0 \\
PPG & 33 & 100 \\
glycerol & 10.8 & 10.9 \\
water & 4.2 & 4.5 \\
silicone surfactant & 7.5 & 8.9 \\
DBT & 0.2 & 0.2 \\
Isocyanate & 294 & 300 \\
Isocyanante index & 100 & 100 \\
\hline
\end{tabular}

Units are in parts per hundred parts (pphp).

The foaming process was monitored by recording cream time and rising time. Suitably fast cream time and rising time are important characteristics of such PU systems. The cream time and the free rise time are reported in Figure 7. Similar cream times were observed for all the formulations, regardless of the bio-polyols used. Moving to the rise time, several differences appear. The rising of foams was completed in 60-140 s, with higher rise times achieved with foams from 3-phenyl butyric acid (Tolo 10 and Tolo 11). This aspect could be ascribed to the different polarities of the side chain in bio-polyols coming from 3-phenyl butyric and caprylic acid, respectively, that influence the miscibility with water. Moreover, the reactivity of prepolymers from 3PBA could be influenced by steric hindrance due to the aromatic motive in $\alpha$ position to isocyanate groups. The presence of aromatic side chains in prepolymers leads to longer rise times also in comparison with the reference foam.

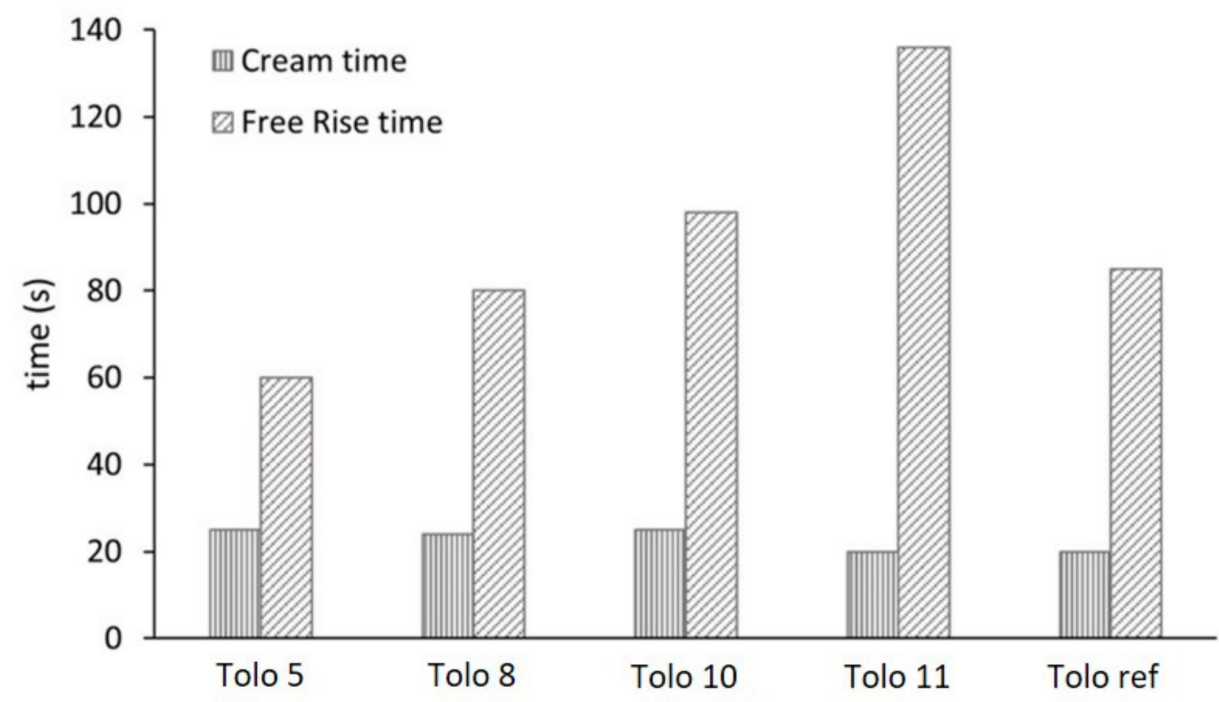

Figure 7. Effect of the different bio-polyols on cream and free rise time.

The free rise time is strictly associated with density of foams (Table 4), where a slower foaming reaction time leads to higher density.

The PU foams were investigated by FTIR spectroscopy and the spectra are shown in Figure 8. The chemical structure of flexible polyurethane foams consists of alternating of urethane and urea linkage domains [37] and in the range from 1640 to $1780 \mathrm{~cm}^{-1}$, the carbonyl stretching vibrations (hydrogen bonded and nonhydrogen bonded) of urethane and urea groups are identified in Figure 8. In detail, all the spectra are characterized by a main absorption peak centered at $1714 \mathrm{~cm}^{-1}$ due to hydrogen-bonded urethane ordered $\mathrm{C}=\mathrm{O}$ groups and carbonyl of free urea close to $1700 \mathrm{~cm}^{-1}$ [38]. This strong absorbance shows a shoulder at $1737 \mathrm{~cm}^{-1}$ in the spectra from bio-polyols, due to the $\mathrm{C}=\mathrm{O}$ stretching of ester group in triglycerides. In the range from 1500 to $1560 \mathrm{~cm}^{-1}$ the absorption peaks related to the $\mathrm{N}-\mathrm{H}$ bond of urea and to $\mathrm{C}-\mathrm{N}$ bond of urea and urethane are observed (the 
details are reported in Table 1 in Supplementary Materials). The overlapping bands of hydrogen-bonded urea carbonyls, including both monodentate (disordered) and bidentate (ordered), are observed around 1650-1670 $\mathrm{cm}^{-1}$ and are indications of hydrogen bonds of differing geometries. Indeed, FTIR analysis shows that the foams prepared with bio-polyols possess the same hard segment structure with respect to those prepared with a standard polyether polyol. All isocyanates groups were reacted with hydroxyl groups to form urethane groups, thus explaining the absence of the peak of the isocyanate group around $2260 \mathrm{~cm}^{-1}$ and $-\mathrm{OH}$ groups around $3510 \mathrm{~cm}^{-1}$. The complete conversion of hydroxyl and isocyanate groups confirms the cross-linking reaction in the employed reaction conditions. The peak at wavelength of $3335 \mathrm{~cm}^{-1}$, corresponding to $\mathrm{N}-\mathrm{H}$ stretching vibration, confirms the reaction between hydroxyl and isocyanates groups, for all PUF spectra. The absorption peaks observed in the range from 1344 to $1460 \mathrm{~cm}^{-1}$ are due to $-\mathrm{CH}$ bend in alkanes [39] and those at $1100 \mathrm{~cm}^{-1}$ are assigned to stretching vibration of ether $\mathrm{C}-\mathrm{O}-\mathrm{C}$ bond in the PPG chain.

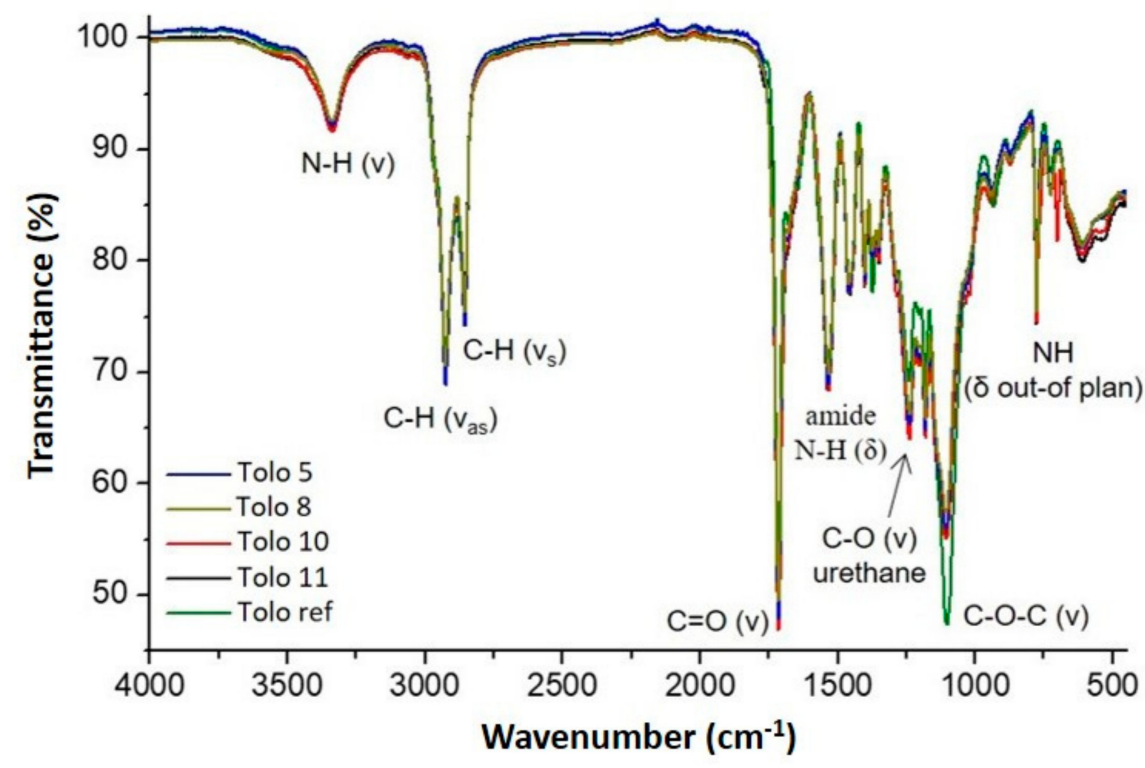

Figure 8. FTIR spectra of the different PUFs.

The apparent density of PUFs is reported in Table 4 , along with strut thickness. The apparent high density of all PUFs was in the range of $79-113 \mathrm{~kg} / \mathrm{m}^{3}$, due to low amount of blowing agent. The highest density value was obtained for foams from 3-phenyl butyric acid.

Table 4. Density and strut thickness of PU (polyurethane) foams.

\begin{tabular}{|c|c|c|c|}
\hline Sample & $\begin{array}{c}\text { Bio-Polyol } \\
\text { Composition }\end{array}$ & $\begin{array}{c}\text { Density }^{2} \\
\left(\mathrm{~kg} / \mathrm{m}^{3}\right)\end{array}$ & Strut Thickness $(\mu \mathrm{m})$ \\
\hline Tolo 5 & $\mathrm{ESO}, \mathrm{CA}$ & $79 \pm 6$ & $35 \pm 6$ \\
\hline Tolo 10 & ESO, 3PBA & $110 \pm 5$ & $36 \pm 10$ \\
\hline Tolo 8 & $\mathrm{ELO}, \mathrm{CA}$ & $102 \pm 2$ & $26 \pm 7$ \\
\hline Tolo 11 & ELO, 3PBA & $113 \pm 1$ & $37 \pm 8$ \\
\hline Tolo ref & - & $88 \pm 10$ & $39 \pm 5$ \\
\hline
\end{tabular}

${ }^{1} \mathrm{ESO}=$ epoxidized soybean oil, $\mathrm{CA}=$ caprylic acid, $\mathrm{ELO}=$ epoxidized linseed oil, 3PBA = 3-phenyl butyric acid ${ }^{2}$ Determined according to ISO 845:2006.

The initial viscosity of bio-polyols is one of the most important factors which influence the cellular structure of the resultant foams, affecting the generation and distribution of the cells formed by the blowing agent [40]. The relatively high viscosity of the bio-polyols (Table 2) with respect to the reference PPG (viscosity equal to $0.63 \mathrm{~Pa} \cdot \mathrm{s}$ ) facilitates the formation of the framework of the urethane group in the stage of the gel reaction between 
the bio-polyol and isocyanate with a low concentration of gel catalyst, resulting in a dense structure and in the high apparent density of the prepared foams, in particular at low water concentration [22,29] and when the aromatic group is inserted in the vegetable oil backbone (Tolo 10 and 11).

Figure 9 shows representative images obtained by optical microscope for selected produced foams, Tolo 8 and Tolo ref, at two different magnifications $(10 \times$ and $30 \times)$.
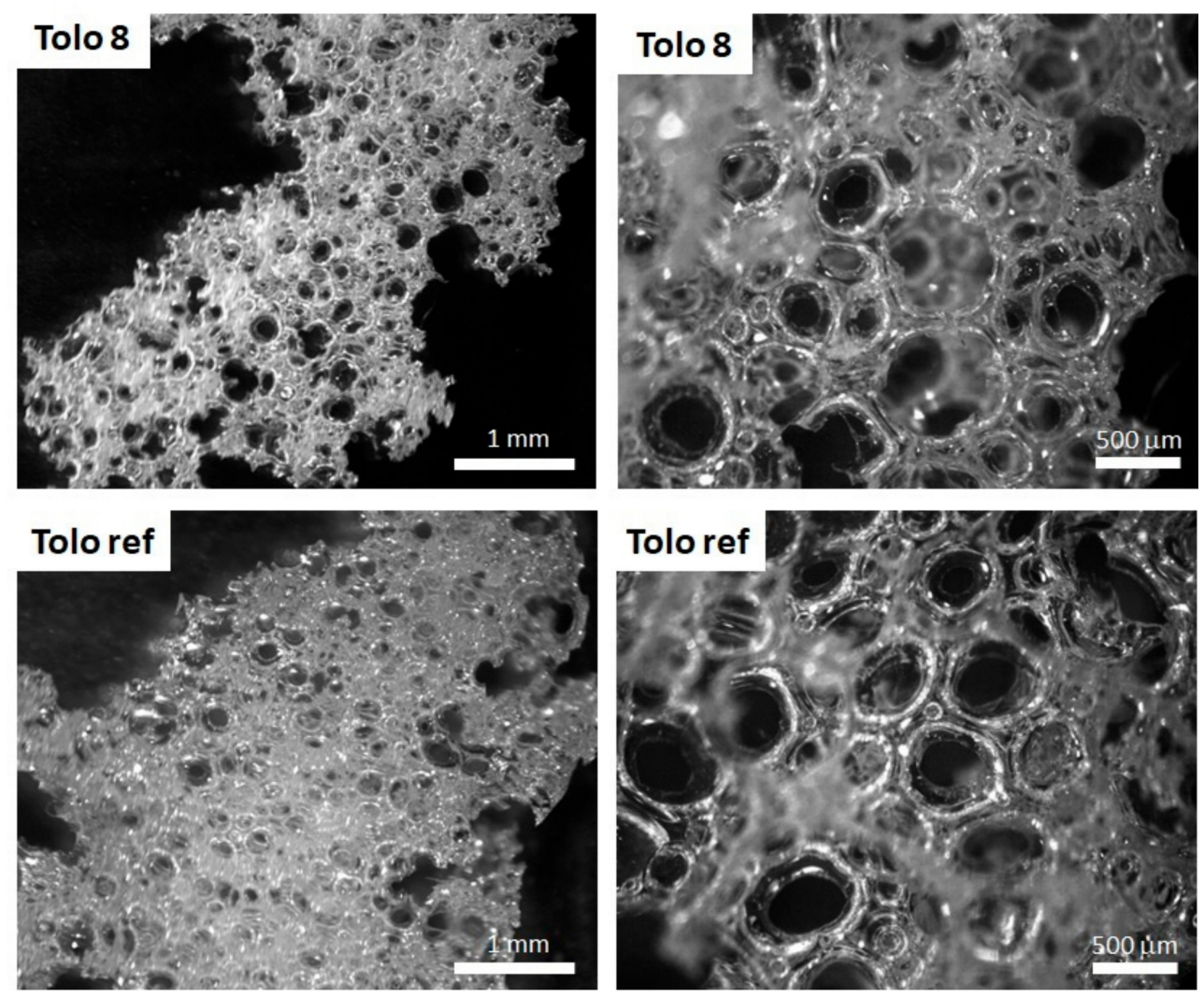

Figure 9. Optical microscope images of Tolo 8 and Tolo ref at different magnifications $(10 \times$ and $30 \times)$.

The bio-based foams showed an open cell structure, with a well-developed cavity network, containing interconnected pores (Figure 9 and Figure S8 in the Supplementary Materials). The foam cells have regular and spherical shape and almost uniform size, indicating the isotropic growth of the bubble during the foaming process.

In the foaming process, the slow gelling reaction rate allowed the bubbles to easily escape from the matrix thus forming completely opened cells before they form the firm struts (Figure 9 and Figure S8 in the Supporting Materials). The foaming process produces, especially in bio-based foams, structures with cavities filled by several interconnected pores. The average strut thickness and the average cavity size are closely related to the density of the foams. In Figure 10, the average cavity and pore size distributions for the different studied systems are reported. The foams obtained from 3-phenyl butyric acid (Tolo 10 and Tolo 11) show smaller average cavity size that impacts negatively on density, despite larger pores being present in these foams. As mentioned above, the presence of aromatic moieties that impact on polyol viscosity can create smaller cavities with larger pores surrounded by thicker walls, increasing the strut thickness in comparison with other bio-based foams and negatively impacting on density. 

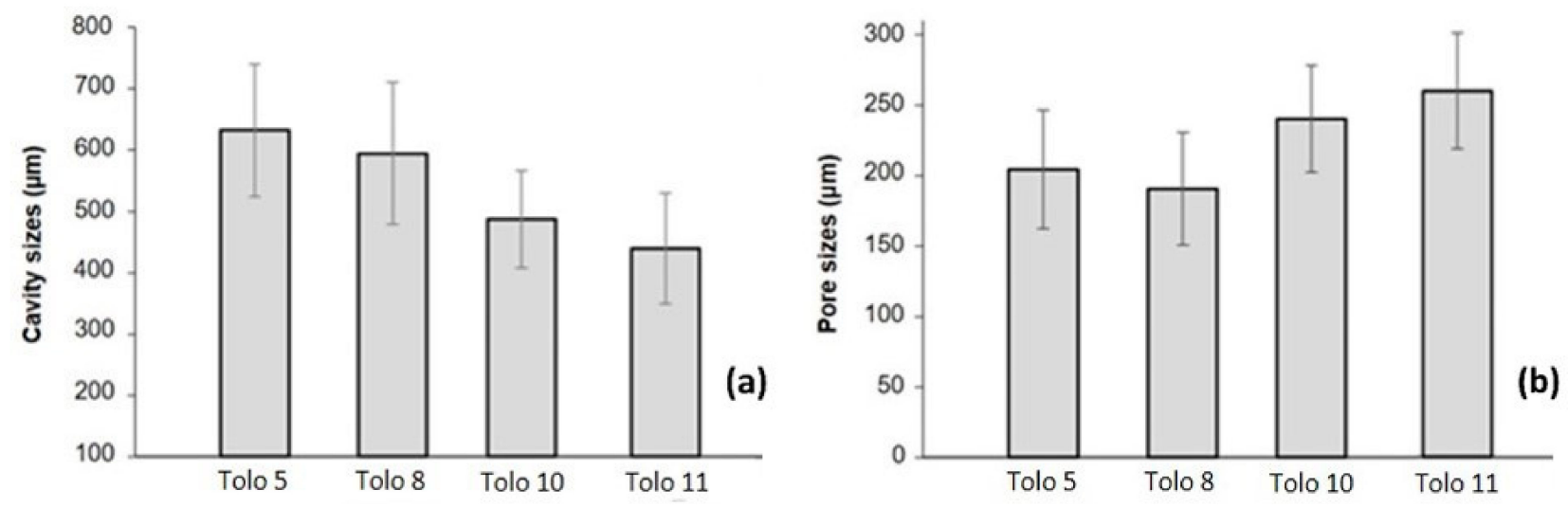

Figure 10. Average cavity (a) and pore (b) size of the PU foams.

Unlike bio-based foams characterized by a cavity-pore structure, a more uniform structure was noticed in the reference foam, with an average pore size of about 400-600 $\mu \mathrm{m}$.

Dynamic TGA and DTG curves of the different polyurethanes and the characteristic degradation temperatures are shown in Figure 11 and Table 5, respectively. Thermograms of PU foams show multiple stages of thermal decomposition under inert atmosphere (Figure 11a). In general, the first mass loss stage observed in the range from 200 to $320^{\circ} \mathrm{C}$ is associated with ca. $40 \%$ of the mass loss and is ascribed to the dissociation of the urethane bonds [41], whereas the successive decomposition stage takes place at higher temperatures (from 320 to $500{ }^{\circ} \mathrm{C}$ ) and is the result of chain scission in the polyol/bio-polyol structures [42]. In particular, the DTG curve for the latter decomposition step exhibits a broad complex signal constituted by successive degradation events for each sample (Figure 11b). It is worth nothing that at this decomposition stage, the reference foam degrades faster than the foams obtained from bio-polyols; indeed, the mass residue at $400{ }^{\circ} \mathrm{C}$ for Tolo ref is close to $15 \%$ whereas for Tolo $\mathrm{x}$ foam is comprised between 21 and $28 \%$. TGA experimental data including the temperature at which the initial $5 \%$ mass loss occurs $\left(T_{5 \%}\right)$ and the temperatures of maximum rate of mass loss $\left(T_{\max }\right)$ determined by main DTG peaks are summarized in Table 5. Considering the $T_{5}$ values (from 253 to $261{ }^{\circ} \mathrm{C}$ ), the differences in thermal stability of the Tolo $x$ foams appear to be slight: a decreasing $\mathrm{OH}$ number of the bio-polyol led to a decreasing number of urethane bonds in the PU foams, and therefore improved thermal stability in the first decomposition stage. Lastly, the differences in $T_{\max }$ values and DTG peak intensities at the second degradation step result are more marked, but there was no obvious trend for these data $[43,44]$.
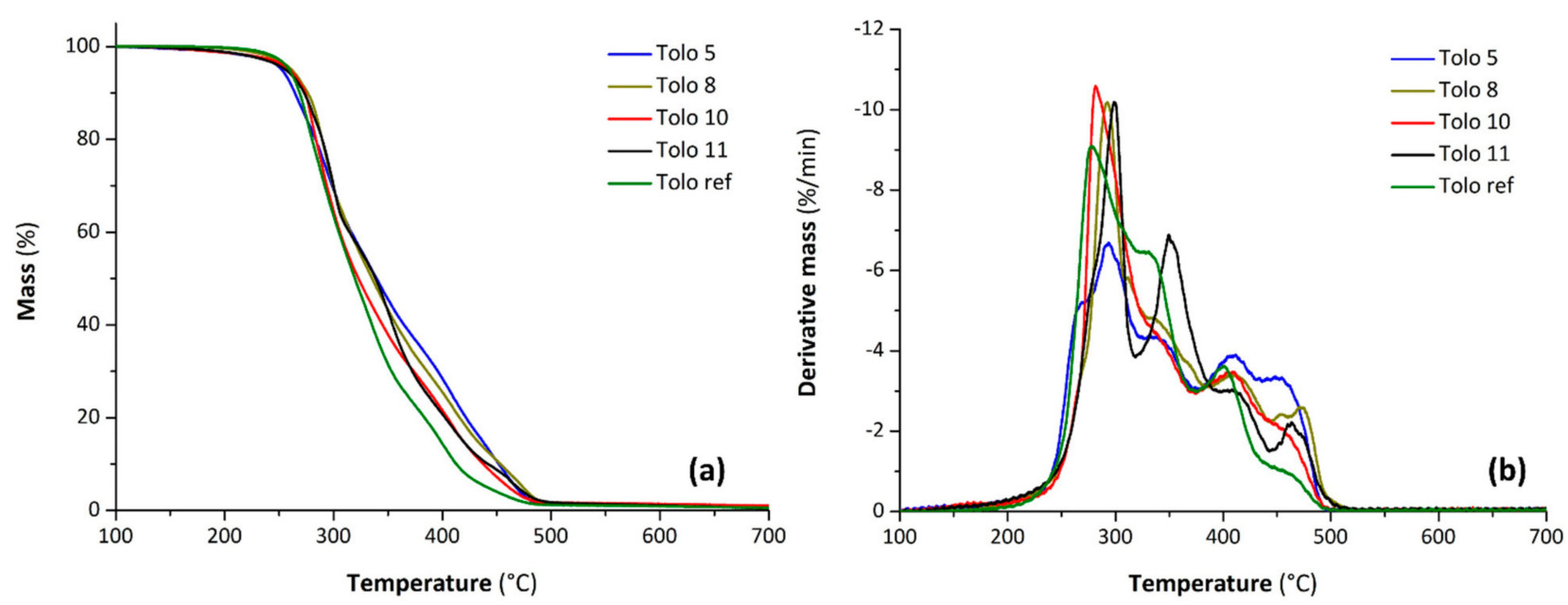

Figure 11. Thermogravimetric analysis (a) and derivate thermogravimetry (b) curves of PU foams. 
Table 5. Thermal and mechanical properties of PU foams.

\begin{tabular}{|c|c|c|c|c|}
\hline \multirow[b]{2}{*}{ Sample } & \multicolumn{2}{|c|}{ TGA } & \multicolumn{2}{|c|}{ Compressive Tests } \\
\hline & $\begin{array}{l}T_{5 \%} \\
\left({ }^{\circ} \mathrm{C}\right)\end{array}$ & $\begin{array}{l}T_{\max } \\
\left({ }^{\circ} \mathrm{C}\right)\end{array}$ & $\begin{array}{c}\text { Young's Modulus } \\
\text { (kPa) }\end{array}$ & $\begin{array}{c}50 \% \text { Compression } \\
\text { Deflection Value (kPa) }\end{array}$ \\
\hline Tolo 5 & 253 & $293,339,411,454$ & $18 \pm 4$ & $4.8 \pm 1.1$ \\
\hline Tolo 8 & 261 & $291,335,408,472$ & $17 \pm 4$ & $5.5 \pm 0.4$ \\
\hline Tolo 10 & 259 & 281,409 & $13 \pm 5$ & $5.0 \pm 1.8$ \\
\hline Tolo 11 & 256 & $299,349,464$ & $14 \pm 1$ & $4.6 \pm 0.5$ \\
\hline Tolo ref & 259 & $277,331,401$ & $26 \pm 10$ & $7.9 \pm 2.0$ \\
\hline
\end{tabular}

The compressive stress-strain curves of PUFs from different vegetable oils and reference are depicted in Figure 12. Curves of all samples exhibit the typical behavior of polymeric foams characterized by an initial linear portion, due to the elastic deformation of cells, followed by a prominent yield and subsequent progressive increase of the curve related to a partial densification.

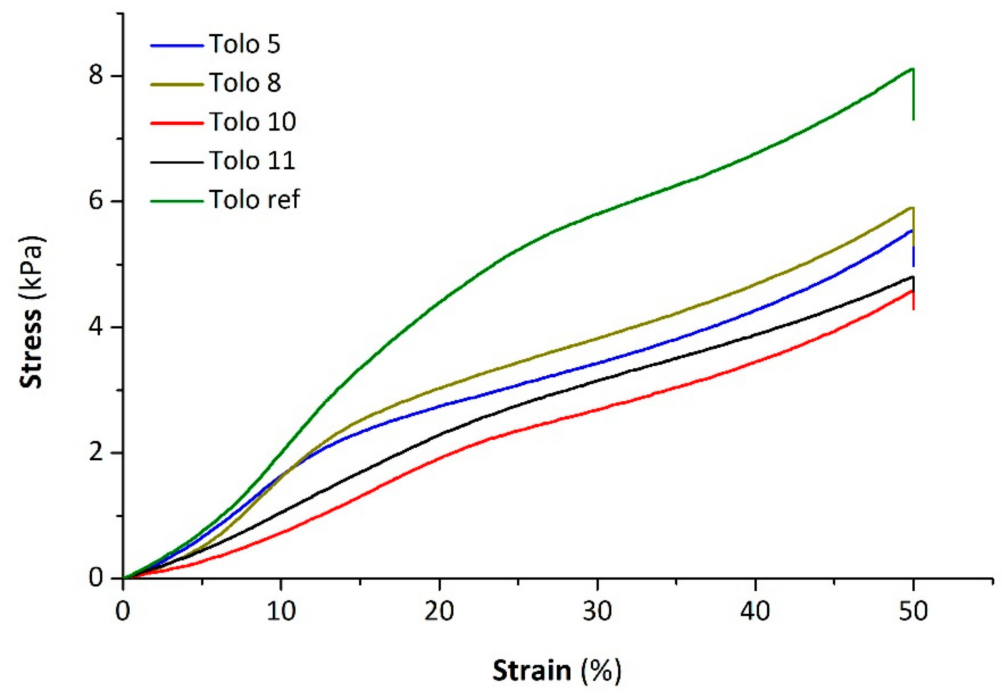

Figure 12. Stress-strain curves of PU foams.

The mean values of the mechanical compressive properties of the samples, namely the Young's modulus and the compression deflection value, calculated as the ratio between the final load and the cross-sectional area of the specimen, are reported in Table 5. The PU foams containing bio-polyols show comparable Young's moduli and compression deflection values, and are slightly lower than the reference foam. Therefore, the presence of biopolyols in the samples leads to more flexibility compared to Tolo ref. In particular, Tolo 10 and Tolo 11 show the lowest compression mechanical properties. This behavior is ascribable to larger average pore size. In fact, as highlighted by Gibson et al., the compression strength of ductile cellular solids is inversely proportional to their cell size [45,46]. However, all the samples exhibit an almost complete recovery of the initial size, that denotes the good elastic properties of the prepared flexible PU foams.

Normalizing Young's moduli and compression deflection values to apparent density is possible to obtain more information about the mechanical behavior of samples. The specific Young's moduli and compression deflection values, shown in Figure 13, highlight the difference between foams containing bio-polyols and the reference sample. Indeed, lower specific mechanical properties were observed for PUFs from bio-polyols compared to Tolo ref. In particular, the foams Tolo 10 and Tolo 11 from 3-phenyl butyric acid exhibit lower compression mechanical performances. 


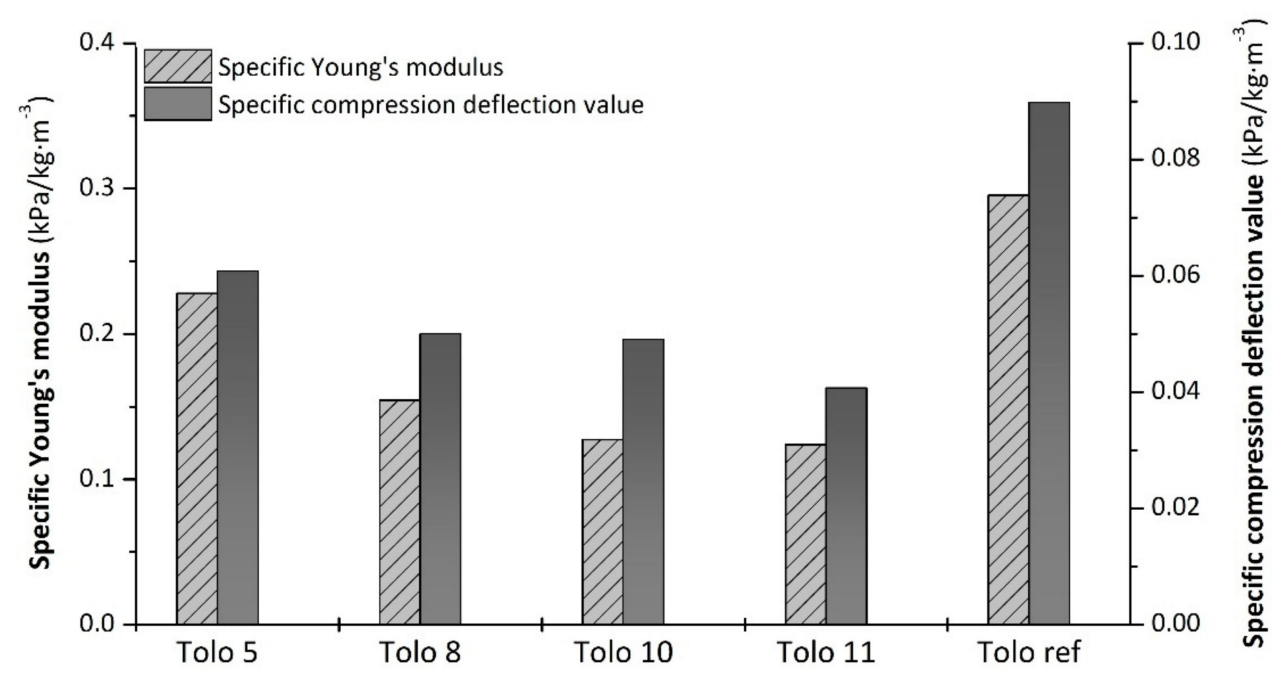

Figure 13. Specific compression properties of PU foams.

Moreover, the difference among Tolo ref and the bio-based Tolo $x$ foams could be ascribed to the morphological characteristics. Indeed, the presence of numerous large cavities, connecting smaller pores, seems to give more flexibility, thus impacting on the final mechanical properties of foams from bio-polyols.

\section{Conclusions}

Bio-polyols were prepared from soybean and linseed oil using a solvent-free method. The main characteristics of synthesized bio-polyols, such as hydroxyl value, acid value, viscosity, average molar mass, and polydispersity could be tailored by controlling reaction conditions, which include reaction time, reaction temperature, and molar ratio of epoxidized oil to organic acid. Bio-polyols are a mixture of several oligomerization products as seen from SEC analysis. The use of TEA, a Lewis base catalyst, leads to polyols in an efficient way, minimizing the formation of cross-linked structures and producing polyols with narrow ranges of polydispersity indices.

The obtained bio-polyols with narrow polydispersity indices (1.1-1.4) and relatively low molecular mass of $1600-2400 \mathrm{~g} / \mathrm{mol}$ were used to prepare flexible polyurethane foams with open cell structures in combination with Tolonate ${ }^{\mathrm{TM}}$, an aliphatic bio-based diisocyanate, that represents a promising material for the synthesis of solvent-free PUs with reduced carbon footprint.

The bio-based foams showed an open cell structure, with a well-developed cavity network, containing interconnected pores. The developed polyurethane foams, with an apparent density in the range of $70-115 \mathrm{~kg} / \mathrm{m}^{3}$, show Young's moduli and compression deflection values that were slightly lower than those of the reference foam.

Supplementary Materials: The following are available online at https:/ / www.mdpi.com/2073-436 0/13/4/612/s1, Figure S1: Effect of the reaction conditions on the molecular weight of bio-polyols from ESO and caprylic acid, Figure S2: ${ }^{13}$ C-NMR spectrum of bio-polyol from ESO and caprylic acid, Figure S3: ${ }^{13} \mathrm{C}-\mathrm{NMR}$ spectrum of bio-polyol from ELO and caprylic acid, Figure S4: ${ }^{13} \mathrm{C}-\mathrm{NMR}$ spectrum of bio-polyol from ESO and 3-phenyl butyric acid, Figure S5: SEC chromatograms of selected bio-polyols, Figure S6: Viscosity of the selected bio-polyols, Figure S7: Representative photos of prepared foam sections, Figure S8. Optical microscope images of Tolo 5, and Tolo 10 and Tolo 11 at different magnifications $(10 \times$ and $30 \times)$, Table S1. Assignments of the main FTIR bands for flexible polyurethane foams. 
Author Contributions: Conceptualization, A.C. and S.L.; methodology, A.C. and F.B.; validation, L.B.; investigation, A.C. and A.V.; data curation, L.B., I.T., F.B, and S.L.; writing-original draft preparation, A.C., F.B. and S.L.; writing-review and editing, A.C., I.T., F.B. and S.L.; supervision, S.L.; project administration, L.B.; funding acquisition, S.L. All authors have read and agreed to the published version of the manuscript.

Funding: This research was funded by CARIPLO FOUNDATION, grant number 2017-0998.

Institutional Review Board Statement: Not applicable.

Informed Consent Statement: Not applicable.

Acknowledgments: The authors thank Fulvia Greco, and Alberto Giacometti Schieroni for their precious technical support. Massimiliano Brivio is thanked for his generous help with the synthesis of bio-polyols.

Conflicts of Interest: The authors declare no conflict of interest.

\section{References}

1. Carr, C.; Ecochard, Y.; Caillol, S.; Avérous, L. From the Synthesis of Biobased Cyclic Carbonate to Polyhydroxyurethanes: A Promising Route towards Renewable Non-Isocyanate Polyurethanes. ChemSusChem 2019, 12, 3410-3430. [CrossRef]

2. Gurunathan, T.; Smita, M.; Sanjay, K.N. Isocyanate terminated castor oil-based polyurethane prepolymer: Synthesis and characterization. Prog. Org. Coat. 2015, 80, 39-48. [CrossRef]

3. Gurunathan, T.; Chung, J.S. Synthesis of aminosilane crosslinked cationomeric waterborne polyurethane nanocomposites and its physicochemical properties. Colloids Surf. A Physicochem. Eng. Asp. 2017, 522, 124-132. [CrossRef]

4. Xu, J.; Fu, C.-Y.; Tsai, Y.-L.; Wong, C.-W.; Hsu, S. Thermoresponsive and Conductive Chitosan-Polyurethane Biocompatible Thin Films with Potential Coating Application. Polymers 2021, 13, 326. [CrossRef]

5. Zhang, C.; An Li, Z.S.; Zhang, Y.-F. RGO-Coated Polyurethane Foam/Segmented Polyurethane Composites as Solid-Solid Phase Change Thermal Interface Material. Polymers 2020, 12, 3004. [CrossRef]

6. Ahmad, A.; Jamil, S.N.A.; Choong, T.S.Y.; Abdullah, A.H.; Mastuli, M.S.; Othman, N.; Jiman, N.N.J. Green Flexible Polyurethane Foam as a Potent Support for Fe-Si Adsorbent. Polymers 2019, 11, 2011. [CrossRef]

7. Lligadas, G.; Ronda, J.C.; Gali, M.; Càdiz, V. Plant Oils as Platform Chemicals for Polyurethane Synthesis: Current State-of-the-Art. Biomacromolecules 2010, 11, 2825-2835. [CrossRef] [PubMed]

8. Pfister, D.P.; Xia, Y.; Larock, R.C. Recent Advances in Vegetable Oil-Based Polyurethanes. ChemSusChem 2011, 4 , 703-717. [CrossRef]

9. Kreye, O.; Mutlu, H.; Meier, M.A.R. Sustainable routes to polyurethane precursors. Green Chem. 2013, 15, 1431-1455. [CrossRef]

10. Fertier, L.; Koleilat, H.; Stemmelen, M.; Giani, O.; Joly-Duhamel, C.; Lapinte, V.; Robin, J.-J. The use of renewable feedstock in UV-curable materials-A new age for polymers and green chemistry. Prog. Polym. Sci. 2013, 38, 932-962. [CrossRef]

11. Ghasemlou, M.; Daver, F.; Ivanova, E.P.; Adhikari, B. Polyurethanes from seed oil-based polyols: A review of synthesis, mechanical and thermal properties. Ind. Crop. Prod. 2019, 142, 111841-111858. [CrossRef]

12. Petrovic, Z.S. Polyurethanes from vegetable oils. Polym. Rev. 2008, 48, 109-155. [CrossRef]

13. Guo, A.; Cho, Y.J.; Petrovic, Z.S. Structure and properties of halogenated and non halogenated soy-based polyols. J. Polym. Sci. A Polym. Chem. 2000, 38, 3900-3910. [CrossRef]

14. Petrovic, Z.S.; Guo, A.; Zhang, W. Structure and properties of polyurethanes based on halogenated and nonhalogenated soy-polyols. J. Polym. Sci. A Polym. Chem. 2000, 38, 4062-4069. [CrossRef]

15. Wang, C.S.; Yang, L.T.; Ni, B.L.; Shi, G. Polyurethane networks from different soy-based polyols by the ring opening of epoxidized soybean oil with methanol, glycol, and 1,2-propanediol. J. Appl. Polym. Sci. 2009, 114, 125-131. [CrossRef]

16. Petrovic, Z.S.; Zhang, W.; Zlatanic, A.; Lava, C.C. Effect of OH/ NCO molar ratio on properties of soy-based polyurethane networks. J. Polym. Environ. 2002, 10, 5-12. [CrossRef]

17. Pan, X.; Webster, D.C. New biobased high functionality polyols and their use in polyurethane coatings. ChemSusChem 2012, 5, 419-429. [CrossRef]

18. Zhang, C.; Li, Y.; Chen, R.; Kessler, M.R. Polyurethanes from Solvent-Free Vegetable Oil-Based Polyols. Sustain. Chem. Eng. 2014, 2, 2465-2476. [CrossRef]

19. Roh, Y.; Rajesh, R.; Zhao, C.L.; Kaczan, D.; Smiecinski, T.M. Polyol Formed from an Epoxidized Oil. U.S. Patent No. 8,308,975 B2, 13 November 2012.

20. Supanchaiyamat, N.; Shuttleworth, P.S.; Hunt, A.J.; Clark, J.H.; Matharu, A.S. Thermosetting resin based on epoxidised linseed oil and bio-derived crosslinker. Green Chem. 2012, 14, 1759-1765. [CrossRef]

21. Poussard, L.; Lazko, J.; Mariage, J.; Raqueza, J.-M.; Duboisa, P. Biobased waterborne polyurethanes for coating applications: How fully biobased polyols may improve the coating properties. Prog. Org. Coat. 2016, 97, 175-183. [CrossRef]

22. Sonnenschein, M.F.; Koonce, W.A. Encylopedia of Polymer Science and Technology, 4th ed.; John Wiley \& Sons, Inc.: New York, NY, USA, 2011; pp. 26-73. [CrossRef] 
23. Sonnenschein, M.F.; Wendt, B.L. Design and formulation of soybean oil derived flexible polyurethane foams and their underlying polymer structure/property relationships. Polymer 2013, 54, 2511-2520. [CrossRef]

24. Marcovich, N.E.; Kurańska, M.; Prociak, A.; Malewska, E.; Kulpab, K. Open cell semi-rigid polyurethane foams synthesized using palm oil-based bio-polyol. Ind. Crop. Prod. 2017, 102, 88-96. [CrossRef]

25. Raymond, M.P.; Bui, V.T. Epoxy/castor oil graft interpenetrating polymer networks. J. Appl. Polym. Sci. 1998, 70, 1649-1659. [CrossRef]

26. Parida, D.; Nayak, P.; Mishra, D.K.; Lenka, S.; Nayak, P.L.; Mohanty, S.; Rao, K.K. Polymers from renewable resources. VIII. Thermal properties of the interpenetrating polymer networks derived from castor oil-isophorone diisocyanate-polyacrylamides. J. Appl. Polym. Sci. 1995, 56, 1731-1738. [CrossRef]

27. Das, S.; Pandey, P.; Mohanty, S.; Nayak, S.K. Influence of NCO/OH and transesterified castor oil on the structure and properties of polyurethane: Synthesis and characterization. Mater. Express 2015, 5, 377-382. [CrossRef]

28. Salih, A.M.; Ahmad, M.B.; Ibrahim, N.A.; Dahlan, K.Z.H.M.; Tajau, R.; Mahmood, M.H.; Yunus, W.M.Z.W. Synthesis of Radiation Curable Palm Oil-Based Epoxy Acrylate: NMR and FTIR Spectroscopic Investigations. Molecules 2015, 20, 1419-14211. [CrossRef]

29. Szycher, M. Structure-Property Relations in Polyurethanes from: Szycher's Handbook of Polyurethanes, 2nd ed.; CRC Press: London, UK, 2012; pp. 37-88. [CrossRef]

30. Latere Dwan'isa, J.-P.; Mohanty, A.K.; Misra, M.; Drzal, L.T.; Kazemizadeh, M. Biobased polyurethane and its composite with glass fiber. J. Mater. Sci. 2004, 39, 2081-2087. [CrossRef]

31. Seydibeyoglu, M.O.; Manjusri Misra, M.; Mohanty, A.; Blaker, J.J.; Lee, K.-Y.; Bismarck, A.; Kazemizadeh, M. Green polyurethane nanocomposites from soy polyol and bacterial cellulose. J. Mater. Sci. 2013, 48, 2167-2175. [CrossRef]

32. Lebas, C.; Turley, P. Primary hydroxyl content in polyols-evaluation of two nuclearmagnetic resonance (NMR) methods. J. Cell. Plast. 1984, 20, 194-199. [CrossRef]

33. Zhu, Q.; Zhang, C.; Feng, S.; Chen, J. Effects of the o-aromatic ring in the molecular chain on the properties of polyester polyols. J.Appl. Polym. Sci. 2002, 83, 1617-1624. [CrossRef]

34. Hiemenz, C.P.; Lodge, T.P. Polymer Chemistry, 2nd ed.; Taylor \& Francis: Boca Raton, FL, USA, 2007; pp. 338-339. [CrossRef]

35. Bayrak, A.; Kiralan, M.; Ipek, A.; Arslan, N.; Cosge, B.; Khawar, K.M. Fatty Acid Compositions of Linseed (Linum Usitatissimum L.) Genotypes of Different Origin Cultivated in Turkey. Biotechnol. Biotechnol. Equip. 2010, 24, 1836-1842. [CrossRef]

36. Clemente, T.E.; Cahoon, E.B. Soybean Oil: Genetic Approaches for Modification of Functionality and Total Content. Plant Physiol. 2009, 151, 1030-1040. [CrossRef]

37. Sung, G.; Kim, S.K.; Kim, J.H.J.W.; Kim, J.H.J.W. Effect of isocyanate molecular structures in fabricating flexible polyurethane foams on sound absorption behavior. Polym. Test. 2016, 53, 156-164. [CrossRef]

38. Coleman, M.M.; Skrovanek, D.J.; Hu, J.; Painter, P.C. Hydrogen Bonding in Polymer Blends. FTIR Studies of Urethane-Ether Blends. Macromolecules 1988, 21, 59-65.

39. John, J.; Bhattacharya, M.; Turner, R.B. Characterization of polyurethane foams from soybean oil. J. Appl. Polym. Sci. 2002, 86, 3097-3107. [CrossRef]

40. Ji, D.; Fang, Z.; He, W.; Luo, Z.; Jiang, X.; Wang, T.; Guo, K. Polyurethane rigid foams formed from different soy-based polyols by the ring opening of epoxidised soybean oil with methanol, phenol, and cyclohexanol. Ind. Crop. Prod. 2015, 74, 76-82. [CrossRef]

41. Javni, I.; Petrovic, Z.S.; Guo, A.; Fuller, R. Thermal Stability of Polyurethanes Based on Vegetable Oils. J. Appl. Polym. Sci. 2000, 77, 1723-1734. [CrossRef]

42. Chen, R.; Zhang, C.; Kessler, M.R. Polyols and polyurethanes prepared from epoxidized soybean oil ring-opened by polyhydroxy fatty acids with varying OH numbers. J. Appl. Polym. Sci. 2015, 132, 41213. [CrossRef]

43. Zhang, C.; Madbouly, S.A.; Kessler, M.R. Biobased Polyurethanes Prepared from Different Vegetable Oils. ACS Appl. Mater. Interfaces 2015, 7, 1226-1233. [CrossRef]

44. Gurunathan, T.; Arukula, R. High performance polyurethane dispersion synthesized from plant oil renewable resources: A challenge in the green materials. Polym. Degrad. Stab. 2018, 150, 122-132. [CrossRef]

45. Onck, P.R.; Andrews, E.W.; Gibson, L.J. Size effects in ductile cellular solids. Part I: Modelling. J. Int. J. Mech. Sci. 2001, 43, 681-699. [CrossRef]

46. Andrews, E.W.; Gioux, G.; Onck, P.R.; Gibson, L.J. Size effects in ductile cellular solids. Part II: Experimental results. J. Int. J. Mech. Sci. 2001, 43, 701-713. [CrossRef] 